\title{
Interpreting in Sexual and Reproductive Health Consults With Burma Born Refugees Post Settlement: Insights From an Australian Qualitative Study
}

\begin{abstract}
Amita Tuteja ${ }^{1 *}$, Elisha Riggs ${ }^{1,2}$, Lena Sanci ${ }^{1}$, Lester Mascarenhas ${ }^{1,3,4}$, Di VanVliet ${ }^{3,4}$, Katrina Sangster ${ }^{3,5}$, Kimberley McGuinness ${ }^{3,6}$ and Meredith Temple-Smith ${ }^{1}$

${ }^{1}$ Department of General Practice, University of Melbourne, Parkville, VIC, Australia, ${ }^{2}$ Intergenerational Health, Murdoch Children's Research Institute, Flemington, VIC, Australia, ${ }^{3}$ Isis Primary Care, Hoppers Crossing, VIC, Australia, ${ }^{4}$ Utopia Refugee and Asylum Seekers Health, Hoppers Crossing, VIC, Australia, ${ }^{5}$ Immigrant Health Service, Department of General Medicine, The Royal Children's Hospital Melbourne, Parkville, VIC, Australia, ${ }^{6}$ sis Primary Care, Sunshine, VIC, Australia
\end{abstract}

OPEN ACCESS

Edited by:

Nancy W. Muturi,

Kansas State University, United States

Reviewed by:

Satveer Kaur-Gill,

National University of Singapore,

Singapore

Satarupa Dasgupta,

Ramapo College, United States

*Correspondence:

Amita Tuteja

amita.tuteja@unimelb.edu.au nidhikrishan2014@gmail.com

Specialty section:

This article was submitted to

Health Communication,

a section of the journal

Frontiers in Communication

Received: 26 November 2020

Accepted: 07 January 2021

Published: 18 June 2021

Citation:

Tuteja A, Riggs E, Sanci L,

Mascarenhas $L$, VanVliet $D$,

Sangster K, McGuinness $K$ and Temple-Smith M (2021) Interpreting in

Sexual and Reproductive Health

Consults With Burma Born Refugees

Post Settlement: Insights From an

Australian Qualitative Study.

Front. Commun. 6:633855

doi: $10.3389 /$ fcomm.2021.633855
Interpreters work with health care professionals to overcome language challenges during sexual and reproductive $(\mathrm{SRH})$ health discussions with people from refugee backgrounds. Disclosures of traumatic refugee journeys and sexual assault combined with refugees' unfamiliarity with Western health concepts and service provision can increase the interpreting challenges. Published literature provides general guidance on working with interpreters in primary care but few studies focus on interpretation in refugee $\mathrm{SRH}$ consults. To address this, we explored the challenges faced by providers of refugee services (PRS) during interpreter mediated SRH consultations with Burma born refugees post settlement in Australia. We used qualitative methodology and interviewed 29 PRS involved with migrants from Burma including general practitioners, nurses, interpreters, bilingual social workers, and administrative staff. The interviews were audio-recorded, transcribed, and subjected to thematic analysis following independent coding by the members of the research team. Key themes were formulated after a consensus discussion. The theme of "interpretation related issues" was identified with six subthemes including 1) privacy and confidentiality 2) influence of interpreter's identity 3) gender matching of the interpreter 4) family member vs. professional interpreters 5) telephone vs. face-to-face interpreting 6) setting up the consultation room. When faced with these interpretation related challenges in providing SRH services to people from refugee backgrounds, health care providers combine best practice advice, experience-based knowledge and "mundane creativity" to adapt to the needs of the specific patients. The complexity of interpreted SRH consultations in refugee settings needs to be appreciated in making good judgments when choosing the best way to optimize communication. This paper identifies the critical elements which could be incorporated when making such a judgement. Future research should include the experiences of refugee patients to provide a more comprehensive perspective.

Keywords: interpretation, sexual health, reproductive health, primary care consultations, refugees, migrants, Burma, Myanmar 


\section{INTRODUCTION}

\section{Background}

The United Nations High Commissioner for Refugees (UNHCR) estimates that the refugee population from Burma is the fourth largest refugee population group by country of origin and consists of nearly 1.1 million individuals (United Nations High Commissioner for Refugees, 2019). Most refugees from Burma are hosted by Bangladesh $(906,600)$, Malaysia $(114,200)$, Thailand $(97,600)$ and India $(18,800)$ but 273,000 internally displaced people still live in camps or camp like situations within the country (Humanitarian Crisis Team (Myanmar), 2019). With the help of global resettlement agencies, many Burma born refugees have moved to the English-speaking countries and it has been estimated that 32,655 Burma born people have immigrated to Australia. The state of Victoria $(10,973)$ has the largest group followed by Western Australia (8074) and New South Wales (7128). The settlement areas are equally populated by Bamars and various ethnic minorities from Burma such as Karen, Chin and Rohingyas (Australian Bureau of Statistics, 2019).

Post settlement health initiatives often classify all refugee communities as one homogenous group. This is misleading and can be the cause of low success rates and uptakes of health programs by different refugee groups (Kercood and Morita-Mullaney, 2015; Tyrrell et al., 2016; Ahmed, 2018; Blount and Acquaye, 2018; Wallerstein et al., 2019). Ethnographic studies with people from Burma describe them as gentle and polite, rarely asking any questions or drawing attention to themselves, and answering everything in the affirmative (Barron, 2007; Asian and Pacific Islander American Scholarship Fund, 2014; Culturalatlas.sbs.com.au, 2020). It is reported in literature that Burma born refugees due to prolonged military dominance and long residence in camp boundaries, have limited sense of agency and have little or no previous experience of making choices (Fink, 2009; Wakeman, 2009; McGinnis, 2012; LaMancuso et al., 2016). Health care workers who are familiar with patients who offer presenting complaints, find it challenging to understand the health needs of the refugee community from Burma who are subtle communicators and prefer not to complaint at all (Swe and Ross, 2010; CDC, 2016; Refugee Services for National Partnership for Community Training, 2017). Further, people from Burma despite their single country of origin, have diverse ethnic, cultural and linguistic backgrounds, which can impact the entire spectrum of sexual and reproductive health (SRH). Hence, our decision to focus on people from Burma (McGinnis, 2012; Noyori-Corbett and Moxley, 2017). As, a mark of respect for thousands of migrants who left their homeland and still remember it as Burma, our participants reported that patients preferred to use "Burma" when talking about their homeland. Hence, we use "refugees from Burma" to define our population of interest.

$\mathrm{SRH}$ is recognized as a difficult topic for health care providers to discuss even with English speaking patients (Hinchliff et al., 2004; Dehlendorf and Rinehart, 2010). Reasons include provider discomfort (Tomlinson, 1998), previous inadequate training
(Singh, 2018), limited time (Tao et al., 2000), age of the patient (Bouman and Arcelus, 2001), fear of embarrassing the patient (Temple-Smith et al., 1999) and, at times, doctors lack familiarity with newer sexual practices and behaviors (Sharron et al., 2005). The dilemmas are compounded by language discordance between health care providers and patient (Squires and Jacobs, 2016), presence of a third person, such as the interpreter (Brisset et al., 2013; Mengesha et al., 2018a) and the patient's unfamiliarity with the Western health systems (Tyrrell et al., 2016; Dutta et al., 2018). Disclosures of traumatic refugee journeys, sexual assault, and emotional impacts of loss of family make interpreting particularly demanding in SRH consults for patients from refugee background (McMichael and Gifford, 2010; Foundation House (Victorian Foundation for Surviviors of Torture), 2012; Keygnaert, 2014; Sudbury and Robinson, 2016; Mengesha et al., 2017; Dwivedi et al., 2019). For successful SRH consults in refugee settings both health care providers and interpreters must convey the therapeutic exchange sensitively within the culture specific norms relevant to each refugee community (Ussher et al., 2012; Botfield et al., 2016; Mengesha et al., 2018a; Croucher and Kelly, 2019; Croucher, 2020).

Published guidelines focus on general aspects of working with interpreters in healthcare, given this, there is a need for specific advice to support health care providers to provide SRH services through interpreters to refugee background patients (Queensland Government: Queensland Health, 2007; Tribe and Thompson, 2008; Phillips, 2010; Gray et al., 2012; Brisset et al., 2013; Tyrrell et al., 2016; Migrant and Refugee Women's Health Partnership, 2019).

\section{Study Rationale-Identified Needs}

This paper is a part of a doctoral thesis that aims to explore SRH needs of refugees from Burma. We chose to work with refugees from Burma following a request from a community health centre located in the settlement area. Despite being a refugee clinic, health care providers, faced challenges in providing SRH care that was responsive to the specific needs of this community. This study was initiated by a general practitioner (GP) following a challenging clinical encounter when a Burma born couple arrived at the clinic and were resistant to work with an interpreter (Figure 1).

We have chosen to narrate this incident because it is likely to resonate with the day-to-day practice experience of all health care providers working in primary care with refugee patients. This incident clearly demonstrates the interpretation related challenges that are inherent to bilingual sexual health care particularly in context of refugees from Burma.

Although primary care has been identified as the preferred place to seek treatment for sexual health concerns (World Health Organization, 2016; Department of Health and Human Services (State Government of Victoria), 2017; Department of Health (Australian Government), 2018), there are no published guidelines for health care providers regarding working with interpreters in SRH consultations with people from refugee backgrounds. Some medical anthropologists and social 


\section{Vignette 1}

GP4: There's one particular incident which... which was very awkward when I was speaking to a woman and her husband insisted on being the interpreter. Even, I had tried to suggest that it would be a good idea to have the professional interpreter and the husband would not let this happen. And in fact, it was very awkward, because her initial health screen was positive for syphilis. And she had recently arrived in the country, her husband had been here longer. So, I had to notify them about this diagnosis. So, that was very awkward. Extremely awkward.

The other complication was that this woman was pregnant...that she had got pregnant, sort of, as soon as she arrived in the country. I downplayed the fact that syphilis was sexually transmitted. She had come from a refugee camp so, look, there could have been rape or anything. So, I said, "Look, this is an infection that is, you know, common in the camps, so you could've got syphilis in the camp." But I said how important it was for her to have it treated, especially for the unborn child and that it is important for the husband to be tested. So, it seemed to be O.K. on the surface, I do not know what conversation went on at home.

Then, I fixed a new appointment with an interpreter for follow up and I booked a phone interpreter. I specifically requested a female as there is no way women will talk through male interpreters. I booked an interstate interpreter same as we do for people who are HIV positive .... because, you know, it's a small community. There is a real worry about their health information getting spread amongst the community.

Interviewer: So, did they eventually agree?

GP4: Yes, but then I had to examine the patient and discuss collection of swabs. To get to the examination couch was quite a challenge. And to discuss the dynamics of genital examination on a couch with a phone interpreter, I think that is really difficult. I remember that I had to call out very loudly "Is there any pain where I'm touching?". And, you know, and it's an intimate thing this examination, and it really destroyed the atmosphere to yell out "Any pain?" and sometimes the interpreter couldn't hear me on phone and kept saying, "Sorry, I can't hear.". Then, I had to come out from behind the curtain, come up to the phone and then address the interpreter which I do not like doing. I like always addressing the patient. So, I said, "Can you ask them to tell me is there any pain where I'm touching you?" and then I had to go back in and out many times before completing the examination.

So, I will do a lot of miming, and showing that I want to feel the heart, or I want to check in the ears. So, this is not too bad, but it is quite difficult if it is a genital examination.

As it tumed out she had other STDs, and so did her husband. In the end I got an onsite interpreter with whom they shared their worries and who said that the patients were terrified that they will be thrown out of the country because they have some disease. Once I figured out what was troubling them. I tried to clarify as much as possible and reassure them that treatment is available and they both did take the treatment. So, you see it is different compared to English speaking patients.

FIGURE 1 | Excerpt of an interview with a GP (General Practitioner) working with refugees from Burma.

scientists have documented the gaps in guidance around sense of control in interpreter mediated interactions and have cited examples of reproductive health consults (Robb and Greenhalgh, 2006; Hsieh, 2010; Leanza et al., 2010; Brisset et al., 2013; Mengesha et al., 2018b).

We go a step beyond to explore the dynamics of these sensitive consults from the perspectives of providers of refugee services' (PRS) and then systematize the challenges faced. Within the Australian context there are many professionals involved in providing such services post settlement. In this study PRS includes health care professionals (doctors, nurses, midwives), bilingual support staff (interpreters, social workers, settlement workers, community liaison officers) and administrative staff (practice managers, reception staff) who work jointly to provide primary care services to refugees.

\section{Theoretical Framework}

We selected the Communication Accommodation Theory (CAT) (Giles et al., 1991; Street, 1991) as the framework to guide the study design, data collection, interpretation, and analysis of our qualitative data. CAT focuses upon how, when, and why speakers adapt their messages to match that of their interlocutors (accommodation) or not (non-accommodation) and the ways in which conversation conflicts can be managed (Jain and 
TABLE 1 | Participant demographics.

\begin{tabular}{|c|c|c|c|c|c|}
\hline & $\begin{array}{c}\text { GPs } \\
N=6\end{array}$ & $\begin{array}{l}\text { Nurses } \\
N=9\end{array}$ & $\begin{array}{c}\text { Practice } \\
\text { Managers } \\
N=3\end{array}$ & $\begin{array}{l}\text { Social Practitioners } \\
\qquad N=6\end{array}$ & $\begin{array}{l}\text { Interpreters } \\
\qquad \mathbf{N}=\mathbf{5}\end{array}$ \\
\hline Gender & $\begin{array}{l}3 \text { females } \\
3 \text { males }\end{array}$ & All female & All female & All female & $\begin{array}{l}3 \text { females } \\
2 \text { males }\end{array}$ \\
\hline $\begin{array}{l}\text { Mean Age } \\
\text { (Range) }\end{array}$ & $\begin{array}{l}48 \text { years } \\
(35-64)\end{array}$ & $\begin{array}{l}55 \text { years } \\
(43-66)\end{array}$ & $\begin{array}{l}51 \text { years } \\
(38-66)\end{array}$ & $\begin{array}{l}37 \text { years } \\
(30-45)\end{array}$ & $\begin{array}{l}34 \\
(28-44)\end{array}$ \\
\hline $\begin{array}{l}\text { Ethnic background } \\
\text { (self-defined) }\end{array}$ & $\begin{array}{l}3 \text { Australian } \\
1 \text { Indian } \\
1 \text { Burmese } \\
1 \text { Anglo-Saxon }\end{array}$ & $\begin{array}{l}4 \text { Australian } \\
1 \text { Anglo-Saxon } \\
1 \text { Indian } \\
1 \text { Dutch } \\
1 \text { Italian } \\
\text { 1-British }\end{array}$ & $\begin{array}{l}1 \text { Australian } \\
2 \text { Anglo-Saxon }\end{array}$ & $\begin{array}{l}3 \text { Australian } \\
2 \text { Karen } \\
\text { 1-Chin/ Burmese }\end{array}$ & $\begin{array}{l}3 \text { Karen } \\
1 \text { Chin/ } \\
\text { Burmese } \\
1 \text { Karen/ } \\
\text { Burmese }\end{array}$ \\
\hline $\begin{array}{l}\text { Language Proficiency } \\
\text { (First Language) }^{\mathrm{a}}\end{array}$ & $\begin{array}{l}5 \text { English } \\
1 \text { Burmese }\end{array}$ & 9 English & 3 English & $\begin{array}{l}4 \text { English } \\
3 \text { Burmese } \\
2 \text { Karen } \\
1 \text { Thai } \\
1 \text { Chin }\end{array}$ & $\begin{array}{l}2 \text { English } \\
2 \text { Karen } \\
1 \text { Chin } \\
1 \text { Burmese }\end{array}$ \\
\hline $\begin{array}{l}\text { Language Proficiency } \\
\text { (Second }^{\text {Language) }}{ }^{\mathrm{a}}\end{array}$ & $\begin{array}{l}1 \text { Burmese } \\
1 \text { Hindi }\end{array}$ & Nil & 1 French & $\begin{array}{l}2 \text { English } \\
2 \text { Karen } \\
1 \text { Korean }\end{array}$ & $\begin{array}{l}2 \text { English } \\
1 \text { Karen } \\
2 \text { Burmese }\end{array}$ \\
\hline $\begin{array}{l}\text { Experience in health care } \\
\text { Mean } \\
\text { (Range) }\end{array}$ & $\begin{array}{l}26 \text { years } \\
(12-40)\end{array}$ & $\begin{array}{l}31 \text { years } \\
(20-48)\end{array}$ & $\begin{array}{l}31 \text { years } \\
(21-33)\end{array}$ & $\begin{array}{l}5 \text { years } \\
(0-10)^{\mathrm{b}}\end{array}$ & $\begin{array}{l}7 \text { years } \\
(5-8)^{c}\end{array}$ \\
\hline $\begin{array}{l}\text { Experience in refugee health } \\
\text { Mean } \\
\text { (Range) }\end{array}$ & $\begin{array}{l}10 \text { years } \\
(10-18)\end{array}$ & $\begin{array}{l}9 \text { years } \\
(1-15)\end{array}$ & $\begin{array}{l}7 \text { years } \\
(3-10)\end{array}$ & $\begin{array}{l}4 \text { years } \\
(0-10)^{b}\end{array}$ & $\begin{array}{l}7 \text { years } \\
(5-8)^{c}\end{array}$ \\
\hline $\begin{array}{l}\text { Proportion of Burmese refugees seen in } \\
\text { practice }\end{array}$ & $\begin{array}{l}75 \\
(50-90)\end{array}$ & $\begin{array}{l}55 \\
(5-90)\end{array}$ & $\begin{array}{l}83 \\
(80-90)\end{array}$ & $\begin{array}{l}80 \\
(60-80)^{d}\end{array}$ & $100^{e}$ \\
\hline
\end{tabular}

Mean \%

(Range \%)

Designated roles in services for refugee $\quad$ Primary care $\quad$ Refugee health nurses

community physicians

Mother and Child Health

nurses

Women's health nurses
Practice managers Community volunteers Interpreters Client service Social workers

Officers Settlement

aSome participants have proficiency in more than one language and have identified with more than one first and second languages.

${ }^{b}$ One social practitioner worked in a non-governmental refugee organization and helped mothers with young children in education, day to day work and occasionally worked in health promotion groups. Therefore, she felt that she had no direct experience in health care.

${ }^{c}$ All the interpreters had always worked in refugee health organizations and had no experience of other settings.

${ }^{d}$ Social practitioners worked with all refugee groups who presented to community health centres and children's play groups, but as the area had predominantly people from Burma, majority of them worked with Burma born families.

eInterpreters participating in the study were selected by purposive sampling and all of them worked with people from Burma.

Krieger, 2011). In other words, CAT highlights individuals' beliefs and motivations underlying the communicative behavior in the immediate situation, either oriented convergently (accommodating) toward or divergently (non-accommodating) away from others present. This analysis model has been successfully applied to study diverse intergroup conversations such as patient provider interactions especially in cross cultural settings (Farzadnia and Giles, 2015).

Although CAT has been applied in patient provider interface, this study fills a gap by applying it to interpreter mediated SRH interactions with patients from refugee backgrounds post settlement in Western countries. CAT is applicable to these settings because it accounts for patients' individuality, communication style, cultural values, and personal preferences and how PRS accommodate for them in triadic cross cultural SRH settings. CAT's convergent and divergent strategies can be effective by conveying a sense of collaboration (e.g., shared decision-making); respecting the other's communication style, level of autonomy, and individuality; created an environment of trust (e.g., sense of equality, role responsibility etc.); and alleviate tension, anxiety, and other negative emotions. Used appropriately, CAT can form the foundations for efficient communication in all SRH appointments.

We also draw from Ellingson's innovative text that explores frontstage and backstage communication in clinical consultations. The work takes on the difficult task of answering the most challenging question about clinical conversations "What is going on here?". We used her starting points to examine the narrated scenarios and understand collaborations and conflicts within interpreter mediated SRH interactions. Her conclusions about power dynamics, diversity, and interdisciplinary teamwork helped us to decipher unrevealed practical issues in day-to-day consultations (Ellingson, 2004). We contend that this can provide insightful clues for service providers, interpreters, and patients regarding what to do communicatively in sensitive SRH conversations. Finally, 
TABLE 2 | Themes and sub-themes.

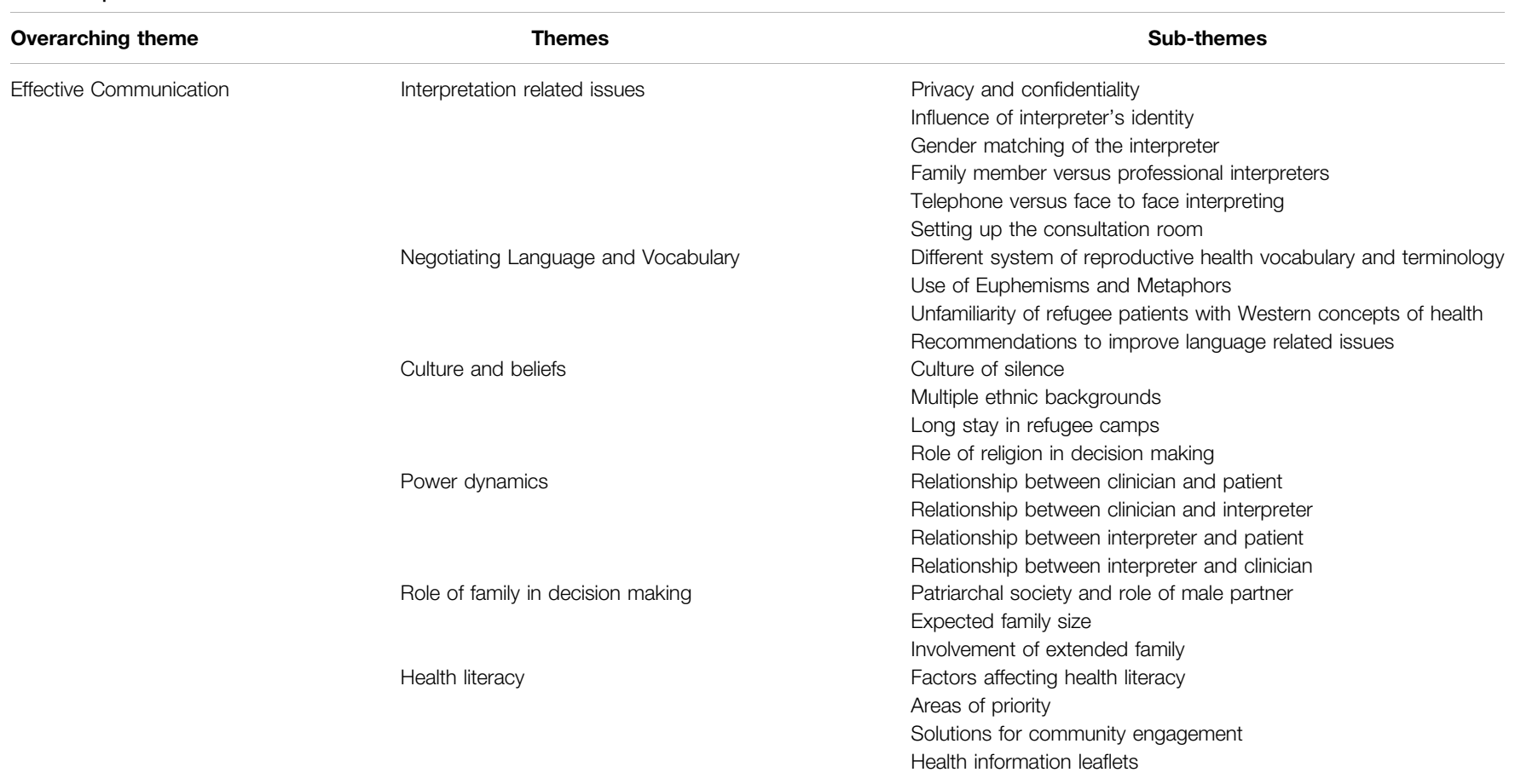

integrating the two frameworks not only ensured robust theoretical grounding in the study design and data collection, but also supported a pragmatic analysis to keep our findings relevant to PRS.

\section{METHODS}

An exploratory qualitative approach was selected because nuances of reproductive health consultations, particularly in refugee settings with communication barriers can be best brought out by talking to experts in the subject (Ulin, 2002). To understand their issues, the $\mathrm{PhD}$ researcher (AT-obstetrician and gynaecologist with keen interest in refugee health) undertook semi structured interviews with 29 PRS with a minimum of 2 years' experience working with refugees from Burma. The interviews were conducted from July 2015 to December 2016. To introduce the readers to AT's experience with qualitative interviewing we have incorporated an auto-ethnographic narrative from her field diary (Ellingson, 2006). AT reflects on her experience of transitioning from a clinician to a qualitative researcher "I had had spent years in practicing clinical interviewing focussed towards establishing a diagnosis. In contrast, now my interviewing strategy involved the art of patiently listening to the participant, letting them guide the conversation and find meaning from their lived experience. I interpret it as a shift from cross sectional interview to an in-depth interview where I have to encourage the participant to narrate their own story". In this account, AT acknowledged her "physician focussed communication" (Mishler, 1984; Feinstein, 1987) style to "patient centred communication" (Smith, 2002;
Levinson et al., 2010). This paradigm shift played a key role in AT's evolution as a qualitative interviewer and reflected in the deepening of content as interviews proceeded to theme saturation.

AT did "bracketing sessions" (Fischer, 2009) with MTS her principal supervisor to document her position and views prior to data collection, and after every coding consensus meeting. AT was a "dynamic researcher" (Morris et al., 1999) trying to integrate her "emic" perspectives in practitioner interviews with "etic" perspectives of cultural nuances of ethnic groups from Burma. Being an émigré gynaecologist, having arrived in Australia for further academic pursuit, AT found herself attracted to the idea of studying reproductive health behaviours of ethnic refugee groups from Burma. She had encountered multiple undocumented refugees in her clinical training and faced tremendous language difficulties as there was no provision of interpreters in most hospitals. After migrating to Australia, AT was strongly motivated to create this research proposal. She reflected that this research promised the potential to reveal and granulate dialectal and cultural barriers faced by medics during diverse refugee and migrant SRH presentations and problems.

We used purposeful sampling and snowballing to maximize diversity (Sandelowski, 2000; Sandelowski, 2010). Variables guiding sampling included age, gender, place of medical training, language proficiency, length of time in Australia and type of practice. As we were working in an area of felt need, enthusiastic participation was noted and consequently theme saturation was achieved. Ethics approval for the research was provided by the Human Ethics Advisory Group of the University of Melbourne. 


\section{Vignette 2}

A patient from Burma presented to the refugee health nurse, requesting termination for an unplanned pregnancy. She refused the services of an interpreter and continued to repeat "my English broken but no interpreter please no interpreter". The very mention of the word interpreter made her very upset and sent her into a fit of tears. Understanding her distress, the nurse spent extra time in calming her and recommended an interstate telephone interpreter. The nurse spent more than an hour to explain that she will not be able to help her to the best of her abilities due to language issues. It was stressed repeatedly that the health service had to involve a professional interpreter to understand the patient's circumstances better. Finally, the patient agreed, and an interstate interpreter was booked. Then, it became evident that the patient was related to the on-site interpreter who was a prominent community and religious leader.

The patient explained that abortion was taboo in their family and the grave consequences included loss of reputation and even a divorce. She specifically requested that no documentation was to be made in her records, and all tests and services be organized covertly. The nurse identified code words to discuss it safely in case there was someone else present. "Have you had your rice today" is a common greeting in Burma used similarly as hello in English and the woman suggested that if she says yes to this question, it means that it is safe to talk about this on the phone or a face to face visit. The surgical termination was conducted at a tertiary hospital and instead of the routine community liaison officer, the same nurse accompanied the patient to the day procedure. The documentation was done at the tertiary hospital with special requests to not send any communication to the practice.

Later, the nurse received a small note in patients' own language saying "you saved my life" which made all this effort worthwhile. However, in terms of practice changes the refugee health nurse correctly reflected that we have a long road ahead for organizing refugee friendly reproductive health services.

FIGURE 2 | Field notes: The need for safe words.

A broad interview guide (Supplementary Appendix S1) with open questions was used to explore different aspects of provider perspectives regarding SRH needs of the refugee community from Burma post settlement in Australia. During discussions, deepening of the content, clarifications, and condensing were achieved with targeted questions where the $\mathrm{PhD}$ researcher relied on her experience as a gynaecologist and integrated both "emic" and "etic" perspectives. The interviews lasted between 60-90 min and were conducted over one to two sessions. 28 out of 29 interviews were audiotaped and then transcribed verbatim. Descriptive and analytic field notes were taken during and immediately after the interview sessions. Descriptive notes included participant's verbal and non-verbal behaviour, context in which these behaviours took place and off record stories with the participant's consent. Analytic notes comprised the PhD researcher's own thoughts, feelings, impressions, and insights (Mulhall, 2003; Muswazi and Nhamo, 2013).

Data were analysed independently by research team members utilizing content analysis, focussing on objective and systematic inductive coding (Graneheim and Lundman, 2004). Field notes were used to "add back" critical non-verbal content into the interview. In addition, relevant observations, narrated off record incidents and critical reflections were added into the content analysis wherever required (Maharaj, 2016). Creation of detailed field notes which were shared with other research team members ensured that the depth of context persisted throughout the analysis. This was expanded to include interpretation of latent content, reflections, and background information (Graneheim and Lundman, 2004). Codes were unanimously agreed by team members to validate the meticulousness and accuracy of data analysis. (Supplementary Appendix S2 Iterative guide for content analysis). All the divergent comments were discussed by the research team to achieve consensus; ambiguities were resolved by considering the deeper meaning and context of the quotation. After the data collection and analysis was completed, the $\mathrm{PhD}$ researcher joined the Obstetrics and Gynaecology Department at a tertiary hospital in Australia and took leave from her $\mathrm{PhD}$ studies. In this "pause period" (Fletcher, 2013, page 5), she undertook a major review of thematic analysis and coding. This allowed her to step back and critically reflect on the data considering her own clinical experience of working with interpreters and women from culturally and linguistically diverse (CALD) backgrounds.

After resuming $\mathrm{PhD}$ studies in 2019, she discussed her interpretation, the connections, and dissonances with the research team members to identify thematic gaps, overlapping themes and added new sub-themes. Throughout the analysis, the research team was continually striving for critical reflexivity: seeking to recognize and unpack the shifting contexts, emotions, social constructs, and 


\section{Vignette 3}

GP 2: It is quite tricky because often we don't know when a particular interpreter in a consult can be a problematic for a patient, and you find out in the middle of a consult. Sometimes, when you can sense the discomfort, you can ask the interpreter to leave and then arrange someone else. I remember a couple where the lady had rheumatic heart disease and her family was complete. After many visits, the couple had still not made a contraceptive decision. We had the same interpreter for all three consults.

In the third consult, I sensed that the man was avoiding eye contact with the interpreter. Instead of putting the patient on the spot, I terminated that consult and booked an interstate phone interpreter for follow up. In the comfort of anonymity, the couple chose to get tubal ligation and opted for a Mirena in the waiting period almost in the first ten minutes of the consult. I had to find out what had changed, and the wife explained that the interpreter is a community elder and against contraception. The couple did not want to hurt his feelings

Interviewer-So if you had missed that subtle clue, there would have been no progress indeed. GP2: If I may say so, I reflect that if I had a meeting prior with the interpreter to explain the context then, I may not have involved him at all.

FIGURE 3 | Conflict sensed in the middle of a consult and re-booked with a different interpreter.

\section{Vignette 4}

Nurse 8: It is common to assume that all people from Burma are Burmese. But it is exactly the opposite in clinical practice. The Burmese can never be clubbed together as one group. There are ethnic tensions between the groups and the majority group Burmans speak Burmese and the rest have their own language. The groups that we see are Karen, Chin, Shan and now we also see Rohingyas. My patients and community workers advise that Karen are Karen and not Burmese. It is better to know about it. Some Karen will know Burmese because it is the national language but will prefer to speak Karen only.

You see it is important for the groups to maintain their identity post migration.

A Karen mother in the initial consult requested that I see her teenage daughter because of painful periods. Our reception staff who was a casual just read that they were from Burma and booked a Burmese interpreter instead. On the day, we had to re-book because the girl spoke only Karen. I was also worried that the interpreters Burmese identity would conflict with the Karen values.

The girl was born in the camp; she had no knowledge of Burmese. The mother said she could try and do a little bit of translation between Burmese and Karen. But I knew there is a lot to discuss in dysmenorrhea, so we just rebooked with a Karen interpreter. At least on the surface I did not sense any Karen or Burmese tensions.

FIGURE 4 | A refugee health nurse describes that it is important to book the correct ethnicity and language matched interpreter prior to the clinical consultation.

power relations that ran through the research. We have since developed a resource of best practice advice regarding "working with interpreters in SRH consultations in refugee settings". We are in the process of obtaining feedback about this resource from the key stake holders and the initial interviews confirm that the sub-themes identified in the current paper are even more relevant than before because of the increasing migration of refugees to Australia.

\section{RESULTS}

Twenty-nine PRS (Table 1) participated from a range of diverse professions including health care professionals (doctors, nurses, midwives), bilingual supporting staff (interpreters, social workers, settlement workers, community liaison officers) and administrative staff (practice managers, reception staff). 


\section{Vignette 5}

GP3: I will tell you an interesting story of providing some sexual therapy. I had a young woman married to an older chap. The man kept complaining about his wife's lack of sexual interest and drive. She on the other hand kept insisting that he did not respect her wishes even when she was not in the mood. He said "Oh, she is never in the mood. I keep begging, almost pleading". The woman said she had too much housework and felt tired all the time.

There was a lot going on here and it looked like the marriage may break as well. I decided to involve two people, a trusted sex therapist and an experienced Karen interpreter. I have been working with this lady interpreter for a long time and did a pre-consultation meeting with all of them.

The sex therapist suggested that we interview each partner separately and then together. The interpreter, being a well-respected older lady in the community was easily accepted into the treatment by the couple. The male revealed his guilt about marrying a younger lady and his pre-mature ejaculation. The wife talked about lack of foreplay and said she got no pleasure in it. We had made some progress and did another meeting to decide what next.

The interpreter suggested that we get them to sit facing each other and we sit on the sides. She said people of her ethnicity rarely talked about sex with each other; it was just not discussed enough. She said, "I know my people".

The sex therapist and I decided that it would be better for the interpreter to open the interview and she can get them talking. It worked, it actually worked. The therapist later added some routine advice about foreplay, masturbation etc. before the act. This was all through the Karen interpreter. You see the lady interpreter was known, accepted, and believed to not talk to other's about people's problems.

We did do a few sessions and the couple came back ecstatic, pregnant and he kept repeating that "happy wife, happy life". I do not think another interpreter would have got the same results.

FIGURE 5 | A challenging clinical encounter where an interpreter and sex therapist resolve a couple's problem.

Six major themes emerged: Negotiating Language and vocabulary, Interpreter related issues, Culture and Beliefs, Power Dynamics, Role of Family in Decision making and Health literacy. Focussed coding identified twenty-five subthemes (Table 2: Themes and sub-themes). The two themes "Negotiating language and vocabulary" and "Interpretation related issues" are considered together for effective communication. The "language and vocabulary" related theme will be discussed in depth in a separate paper. This paper focusses on the "interpretation related issues" theme with its six sub-themes: 1) privacy and confidentiality 2) influence of interpreter's identity 3) gender matching of the interpreter 4) family member vs. professional interpreters 5) telephone vs. face-to-face interpreting 6) setting up the consultation room.

The excerpt in Figure 1 brings forward the multiple challenges encountered by PRS working with refugee families in reproductive health. All PRS echoed this felt need strongly but stressed that some of the communication problems can be anticipated prior to consults. The results section below describe six subthemes that played a crucial role in SRH interactions with interpreters.

\section{Sub Theme 1: Privacy and Confidentiality} All PRS when queried about SRH consultations with refugee communities from Burma, emphasized that privacy and confidentiality are prime concerns in SRH, and patients may feel uneasy by the presence of an interpreter. The PRS explained that, in small communities from refugee backgrounds, there is a high likelihood that patients will know the interpreter.as a member of their community. The five specific issues which made privacy paramount included "sensitive sexual disclosures" (GP5), "traumatic experiences of refugee journeys" (Nurse 7), "unfulfilled reproductive health aspirations" (Social practitioner 4), "partners lost on moving to new countries" (Social practitioner 5), "undisclosed pregnancy outcomes or contraceptive use" (GP2).

To illustrate this, a refugee health nurse shared her experience of arranging surgical termination for a refugee patient from Burma. We summarize her story (Figure 2) to highlight the importance of privacy in accessing reproductive health services. In this particular incident, the interpreter is an English educated religious leader, working as a community advocate and interpreter for monolingual service users. Another example was narrated by an interpreter himself "A lady came for advice regarding accidental condom breakage. She had four children and wanted advice about not falling pregnant. I knew this 


\section{Vignette 6}

Nurse 3: Let me explain with an example. A couple of days ago a male interpreter turned up for a vaginal pessary change session for a Chin lady. She had been recently fitted at the hospital. It appeared that the interpreter had no idea of prolapse, pessaries or intimate matters. I still decided to proceed as I had to examine the patient. You see, on-site interpreters are better than telephone ones.

The woman kept looking towards the floor and the interpreter was speaking monosyllables. As the conversation proceeded it was obvious that I am not going to get anywhere.

After some time, the woman had suddenly become silent and the man looked so uncomfortable. I got him [the male interpreter] to wait outside and organized a phone interpreter, who was a female, and I found out that the pessary had actually fallen out this morning while passing stools. The patient had a UTI. Her husband had tried to have sex last night while the pessary was still in and that had been painful, caused bleeding and made matters worse.

After the appointment, the male interpreter said that the usual lady who interpreted for the agency had called in sick. He said that most ladies of his community were shy and not comfortable with men when discussing personal matters. This could have been a total disaster if I had persisted with the consult.

FIGURE 6 | Gender matching of interpreters with patients.

family through the church. So, I tried to be completely professional in my attitude, but she was so uncomfortable in the situation. Look, I was there to interpret, and it was not my job to say anything. I wish that the GP had paid more attention to the patient's privacy. Sort of ask her if she knew the interpreter outside of the appointment and wanted someone else" (Interpreter 4).

The same observations were echoed by social practitioners "A family was doing it tough. The husband had lost his job and domestic violence was happening in family. I was their case worker, and I knew the husband was trying very hard to improve. They were seeing the GP and the counsellor once a week with me. They were okay about me knowing it because I have been with their family from beginning but they found the presence of the clinic interpreter very awkward. The interpreter knew the lady's parents and the man was worried that the interpreter would tell the lady's family. The doctor off course did not know this background and was not making much progress. It would have been better to ask the family about interpreter preference in such sensitive matters" (Social Practitioner 1).

Despite efforts to identify an appropriate match, patients and interpreters may become uneasy in the presence of each other. These unanticipated reactions between patients and interpreters must be negotiated on the spot within the clinical settings. All GPs found this challenging and reported incidents whereby paying close attention to the non-verbal cues they were able to initiate what proved to be a better outcome for the patient. Consequently, "they either terminated the conversation pre-maturely citing some other reason and arranging a next appointment" (GP5), or "stepped outside the consult and discussed this with the interpreter separately" (GP1) or "at times terminated the phone call and arranged a new phone interpreter" (GP3). To illustrate, we quote a GP who describes how he negotiated this clinical situation in a SRH consultation with a refugee couple from Burma (Figure 3).

\section{Sub-Theme 2: Influence of Interpreter's Identity}

When asked to point out details regarding "characteristics of interpreters," PRS described a multitude of examples to highlight eight different aspects of an interpreter's identity which may have an impact on SRH consults: "interpreter's identity" (Nurse 4), "languages spoken and proficiency" (Nurse 1), "geographic origin" (Practice Manager 1), "ethnicity" (GP2), "religion" (GP5), "social class" (Nurse 7), "education" (Interpreter 3), and "political orientation" (Social practitioner 4). A refugee health nurse (Nurse 8) narrated an incident where an appointment had to be re-booked because the reception staff were not familiar with different ethnicities from Burma (Figure 4). To avoid these ethnic mismatches, a practice manager described cultural orientation to familiarize new staff with the challenges and practicalities of working with refugees from Burma. "If I can give you one take home message regarding interpreters it would be to book the right interpreter for the right person. It may sound simple but in practice it is complicated. Karen will often get Korean interpreters because people have not heard about the Karen. Chin will get Chinese interpreters. Rohingya clients get grouped with people from Bangladesh and often get Bengali interpreters. The sad bit is that the patient will hardly ever say anything and return from the cancelled appointment with unresolved complaints. So now we try and provide a day of cultural orientation to all our staff members" (Practice Manager 2). 


\section{Vignette 7}

Nurse 4: Children often become interpreters for the family. Mothers will come with 10-yearold kids who have English skills expecting them to interpret for the early pregnancy consults. The kids are fine for grocery, getting specs, or even simple stuff like blood tests etc. It is wrong to expect them to participate in complicated adult decisions. It is not okay for me to ask a teenage daughter to ask her mother "If she had bleeding after sex". This is awkward. The child said that she did not know the word for sex.

Coming back to the mother, she was around 6 weeks pregnant, and was having pain and bleeding. The consent of a transvaginal scan was tricky enough. But the lady was having a threatened miscarriage and returned to discuss the options of managing an unplanned pregnancy. She had separated from her partner, but he continued to visit her occasionally. It was very hard for the mum to explain this to the daughter who knew nothing about it.

You see, she was considering terminating the pregnancy. The mother was in a very tight spot. We discussed the options, and I am not sure what happened at home. She returned with the daughter and the father was back in the family and the pregnancy was continuing from then on.

FIGURE 7 | A clinical encounter describing ethical dilemmas that arise when family members are interpreting in SRH consults.

\section{Vignette 8}

GP 3: You see...the people are now settling in Australia and when they do not face restrictions of the camp. Then, things change completely, and people behave differently in this newfound freedom.

A young woman came for her refugee assessment with a girlfriend. They were not aware that I speak Burmese and could understand them. I have spent 5 years in Burma.

The lady was pregnant, and she was sure that the child was from an Aussie partner and was telling this to her friend in Burmese. To me she kept saying that she does not want the pregnancy as her partner is in the camp. She was telling her girlfriend that she met this guy in a bar and I got worried about STDs. The friend or family member was not interpreting for any of these sections and was omitting those facts. I got so worried that I scheduled a follow up the next day with a telephone interpreter and thankfully the friend was not there.

I asked all the right questions, and the patient was honest. We got STD screens done and she was positive for Chlamydia and she named another man who she had been seeing separately and he tested positive later. She opted to continue the pregnancy and said this will be her Australian baby. You see how much changed with having a professional person and the comfort of anonymity.

FIGURE 8 | Family members interpreting in SRH consults may choose to omit vital clinical information.

GP 1 advised that "if we acknowledge the sensitivity of these intimate matters and contact the interpreter before the consultation, say, to simply provide some general facts about the patient, inform about the sexual health context and find out if they will be comfortable interpreting for this patient many communication errors will be avoided". A short narrative (Figure 5) is presented to substantiate the benefits provided by an appropriate interpreter in SRH. In this incident, a GP talks about his predicament when a couple from Burma reporting sexual dysfunction presented to the practice, and how the interpreter's identity played a positive role in organizing an out of the box kind of consult to manage a demanding situation. In this clinical encounter, the GP recognized that the female interpreter's identity was inarguably a re-assuring influence conducive to sensitive disclosures. In a separate example the same GP highlighted how an interpreter's mostly Western upbringing and young age was also helpful in sensitive communications. "A young lady who came to Australia when she was 6 years old and now is a qualified interpreter is also great for our practice. She relates to the Aussie way of life and can talk 


\section{Vignette 9}

GP 2: You can gauge from the body language of the onsite interpreter if they engaged in the consult, if they are following the details of the consult, whether they are following the intricacies of the sensitive matters being discussed. The people from Burma will be quiet and will answer everything as a yes and the information will have to be drawn out of them.

Interpreters are human and it will happen almost always that the interpreter in the room will also make their own judgements about patient's body language and understanding and will seek clarifications when required. Interpreters mean well and will try and fulfill patient's expectations. The person on the phone cannot do so. They will take a very passive role most of the time.

I recall a patient who came for follow up after a cervical biopsy done at the hospital. The family wanted to find out about resuming intercourse and were hesitating to ask me. At the end of the consult, I usually ask people is there anything else, and I had a long silence.

The interpreter sensed the confusion and clarified this information from me, sort of asked this question for them. I let the family know to abstain for next 4 weeks. A person on the phone would never find out.

FIGURE 9 | On-site interpreters to telephone interpreters.

openly in a matter-of-fact manner. That is very useful for the patients and the practitioners. The women's health nurse simply loves her and tries to work with her for almost all patients. This interpreter understands the sexual health issues and makes patients so comfortable" (GP1).

\section{Sub-Theme 3: Gender Matching of the Interpreter}

It is a well-established fact that the patient or interpreter may feel self-conscious or embarrassed about intimate discussions in front of the members of the opposite gender. However, it was still raised by all PRS when questioned regarding problematic situations in $\mathrm{SRH}$ consults with refugees. Even though they characterized gender matching as "common sensical" (GP1), they specified that it not only "facilitated genuine empathy" (Interpreter 3), but in addition "decreased the likelihood of conflicts with the other partner" (GP1). The "embarrassment of discussing intimate problems" (Interpreter 2) in front of a "total stranger of opposite gender were also avoided” (Interpreter 1). A women's health nurse described her blanket rule of gender matching of interpreters and recalled a challenging clinical encounter to explain her reasons (Figure 6). A social practitioner described her own story to highlight the importance of gender matching for refugees from Burma. "When I was pregnant and went to the hospital for checkup, they did not know that I knew English well. They had booked a male interpreter and I did not say anything. The doctor checked my belly in the male interpreter's presence. My top was pulled up and skirt down. My hair down below were showing, I was so embarrassed by his presence. I am sure he was not looking but he should have been behind the curtain or at least someone should have asked me first. I came out feeling so upset. When I cannot speak up for myself and put up with it, ...you can get the picture that people from my community rarely speak up with the fear of upsetting the doctor. To get a lady interpreter for pregnancy checkups would have avoided all these problems" (Social Practitioner 6).

\section{Sub Theme four- Family Member Versus Professional Interpreter}

GP1, the most experienced clinician who had a keen interest in caring for people from Burma explained that it is hard for the refugees from Burma to open up in the presence of a professional interpreter. To quote him "sexual interactions are very private, and occur within close relationships, and are rooted within cultures. I am trying to say that doctors and interpreters are outsiders who are not traditionally accepted in these matters. But when faced with sex troubles, refugees are pressed to involve doctors in the hope that they will resolve these problems. So, I will have to be accepted but I cannot say the same for an interpreter and if a family member speaks English they may be preferred". GP 3 added more insights into the culture "in all ethnic groups from Burma, doctors, nurses, teachers, government people are the most respected group who are implicitly trusted by people and allowed access into their inner worlds. Interpreters do not hold the same therapeutic privileges and may not be accepted by many patients especially in sexual health related matters.".

A women's health nurse narrated an incident where a teenage girl was accompanied by her mother for an appointment. "They both looked very worried and kept discussing irrelevant things. The mother insisted that they did not need an interpreter and the daughter can talk herself. I felt that they did not want an interpreter and requested the booked interpreter to leave the room. The daughter had sufficient English skills to let me know that she was pregnant. She had sex with her boyfriend and did not use protection. She was only sixteen and wanted me to discuss 


\section{Vignette 10}

A triage midwife had phoned the participant who is an interpreter to explain vaginal examination to the patient. The interpreter described that the patient was crying through the examination and saying, "it hurts, it hurts and hurts more".

The participant explained to me that Karen people have gone through a lot before coming to Australia and she asked the patient in Karen if she was alright. The patient blurted out that she had been raped as a teenager by military people and all those memories were coming back to her. The interpreter said that the woman had made her promise not to tell the midwife as she does not want to talk about it and she would be fine.

FIGURE 10 | Excerpt from field notes written after an intensive interview with a Karen interpreter

further options. She had divulged this information to her mother and blurted out that the whole family was not coping at all. I first got them to agree for a professional interpreter on phone and said that we cannot complete this conversation while she interprets for her mother. I assured the pair about anonymity and said its vital to make sure I understand them correctly. They agreed for a professional person interpreting on the phone. In the end she continued the pregnancy and delivered a healthy baby. Look, the point I make is that you cannot expect the teenage girl to interpret for her mother. We will never be sure of the quality of interpretation" (Nurse 4).In contrast, all PRS disclosed that at times, health care services may not have access to trained interpreters and there is no choice but to work with family interpreters or with volunteers who help in the community. For instance, "Karenni interpreters were difficult to arrange as this ethnic community was relatively new in Australia" (GP1). Another example was "walk in appointments where no interpreter was available" (GP 2).

When diverse PRS were specifically questioned about their experiences, they all unanimously voted in favor of professional interpreters. Working with family members was expressed to be problematic because of "ethical issues of confidentiality with sensitive sexual health discussions" (Nurse 4), "family members taking control of the conversation" (GP2), "family members pushing their agendas" (Social practitioner 4), or "offering their own advice and trivializing the doctor's advice” (Nurse 7). Many women's health nurses were concerned that families presented with teenage children and expected them to interpret for their parents (Figure 7). A similar example was narrated by GP 1 when a lady came for help with difficulty in falling pregnant. "Her teenage daughter was with her and the lady insisted that she did not want an interpreter. I could not convince her otherwise and had to proceed with the appointment. As soon as I asked how many times you have sex in a week, the girl looked to the floor and could not ask this question. Off course I stopped immediately and requested the child to wait in the waiting area. I booked an interstate phone interpreter and completed the appointment. This had been so awkward that the patient apologized to me at the end about the inappropriateness of asking her daughter to translate for her".
Nurse 5 also commented that she was surer that "professional interpreters will maintain patient confidentiality compared to family members" and are "bound by the professional code of ethics" (Nurse 2) whereas "family members even with the right intention may accidentally blurt out sensitive patient information in front of other family or community members who should not have been involved" (GP 4). A GP proficient in Burmese as a second language recalled an interesting anecdote to demonstrate the conflicts that may come up due to family members assisting as interpreters (Figure 8).

\section{Sub Theme 5: Telephone Versus Face-To-Face Interpreting}

Overall, the PRS preferred having an on-site interpreter during consultations. Participants (Figure 9) stated that onsite interpreters are more engaged in the consult, their facial expressions of empathy, nods when the patient is speaking, and comforting demeanour improves communication efficacy. Contrary to the "interpreter's code of conduct which states that the interpreters should function as conduits of language translating everything verbatim" (Interpreter 3), PRS found that on-site personnel often provided more help. They served as "cultural brokers" (Nurse 6) and "acted as mediators for both doctors and patients to explain difference in values" (Nurse 8), "helped in addressing conflicts which may be due to interpreter's identity" (Nurse 2) and acted as a "useful resource" (Nurse 3) for the patient as they were aware of service organization and hospital systems. Nurse four recalled a patient consult where the interpreter acted as a cultural broker and resolved the matter easily. "I remember a Chin family came a week after delivery of their first-born child. The mother was feeling unwell and I was not sure what was happening. The perineal stitches had given away and the episiotomy looked infected. I got our GP to examine them and she prescribed antibiotics. They still looked confused and then I asked the interpreter what is happening that I had missed. The lady who was interpreting immediately revealed that in our culture we do not give the new mother anything cold. The patient will not use cold water to wash down below and using ice packs for new 


\section{Vignette 11}

GP 1: I had a couple with problems in falling pregnant. The basic tests were done but I kept thinking I have missed something important. Before referring them on I booked a follow up and decided to elicit a sexual history. I spoke at length to our onsite interpreter and told him to sit behind the patient. It is an unusual arrangement, but I wanted it to feel that they are talking to me and the interpreter is out of their vision. As the conversation proceeded, the female spilled the beans and talked about erectile dysfunction that the man had for years and never talked about it. He initially looked a bit uncomfortable but then began to cry for help. I referred them for further treatment ...but the point I make is getting the interpreter to sit next to the patient does not always work.

Nurse 9: The Chin come for all consults in groups. They may be with family, with children or they may have extended family present. I always get the group to sit in a circle or horseshoe arrangement and the interpreter can sit within the configuration. It is traditional to think of a triangle arrangement where the patient and interpreter sit next to each other. If the patient is attending the appointment alone then this triangle is okay but for a group, the horseshoe or circle works better.

Social Practitioner 6: I work at the reception as a client service officer. When I sit with new arriving families to book all their appointments, I make sure that I sit with them and make them feel at home. With regular patients they can be standing at the desk and make further appointments, but it will not work with Burma born. With people from my country, particularly when they are new, I will always sit with them in a room and book appointments. You see, they get a feeling that they are being listened to and they can seek clarifications. They will not understand women's nurse visit, or Pap smears or breast screens and will just say yes to everything. A family is more likely to speak up the most convenient timings for appointments and not just say yes to anytime that we bring up on the screen when they are sitting with someone whom they trust.

FIGURE 11 | Flexible room layouts for SRH consults.

mums is also against our cultural values. I asked the interpreter to confirm with the patient. Their confused look vanished and they were engaged straight away from then on. We agreed on using warm water washes and I knew that the interpreter had saved the day".

PRS spoke highly of onsite interpreters but all of them also spoke at length about the utility of telephone interpreters service in SRH consults. The telephone services were referred as "faceless interpreters" by a refugee health nurse (Nurse 1) and she was emphatic that "the comfort of anonymity is extremely relevant in contraceptive discussions or sexual issues, say abnormal cervical smears or STDs especially with close knit communities from refugee backgrounds". GP5 added that "we cannot use one size fits all approach when we select interpreters for sexual health appointments, and it is better to decide for every case". To illustrate the utility of working with telephone interpreters PRSs enumerated scenarios where they only worked with phone in services such as "consults with HIV positive people" (Interpreter 1), "first consult with the women's health nurses" (Nurse 7), or "when records clearly stated that patient belonged to the queer community" (Social Practitioner 5). We will quote one of the examples by GP 3 "A Burmese mother came with her adult son to see me. In the first appointment, they talked about something trivial and requested another appointment with a telephone interpreter. It was unusual but I booked a follow up in a week. With the phone interpreter, the mother asked her son to speak frankly to the doctor. He kept looking at the floor and eventually said that I think I like boys more than girls. I did not get it immediately but as soon as it clicked, I was amazed at the supportive mother. The telephone interpreter was understanding and let them talk their heart out. I scheduled multiple follow ups with them and helped the boy come out in open. He eventually moved interstate, but I continued to follow up his well-being through his mother. She has become an advocate for the queer community in refugee people".

Patient examination with telephone interpreters requires special mention in SRH consults. The excerpt in Figure 1 depicts an extremely onerous scenario of having a speaker phone at the desk and examination couch at a distance behind the curtain, where the interpreter on the phone is trying to explain the steps of undressing, speculum insertion and swab collections to the patient. Participants narrated that speaker phones were connected to fixed points on the desks in the consult rooms. When the health care provider and patient move behind the 
curtain for a pelvic or genital examination, the speaker phone is left on the desk at the highest volume with the doctor, patient and interpreter all speaking loudly, while a genital examination is being performed. In other examinations, the health care providers enact or mimic what is required but it is not possible in the genital examination for obvious reasons "you can demonstrate deep breathing but cannot demonstrate speculum insertion with the same ease and reassure the patient" (Nurse 7).

Another example was cited by an interpreter when she was on the speaker phone for a woman in labour (Figure 10). Nurse 3 also described a similar story when she was doing a cervical smear for a Chin lady "The woman started to cry, and it was even before I inserted the speculum. I felt something was not right and I asked the patient if it was okay to proceed, through the phone interpreter. She kept nodding her head and saying yes but tears kept flowing. Look, I was not comfortable and decide to re-book her. When she was dressed, I asked her again if she was okay and if I missed anything. She told me through the interpreter that today was the anniversary of the death of her first husband who had been killed by the military. She had been gang raped while they killed him and later, she miscarried her first pregnancy. I was stunned...completely shocked that all those gruesome memories must be coming back to her. I was so sorry. The telephone interpreter started to cry as well. I hope you get the picture that dealing with refugee women is not as easy as it looks. One has to be extra sensitive and caring towards them".

\section{Sub Theme 6: Setting up the Consultation Room}

Four PRS described that the actual communication process within the consult could be extremely challenging if not well planned in advance. Room lay-out was also emphasized in facilitating communication. "The key is to plan the consult and decide the room layout for every consult" (GP1), and "be flexible to move to a bigger room or add more chairs if needed" (Nurse 8) to ensure ease of triadic dialogue. Nurse 1 outlined scenarios where adapting to the patients' needs improved communication. "The interpreter guidelines talk about triangle consultations. The people from Burma usually come with children for their appointments. They cannot leave children at home nor in an unsupervised play area in the waiting room. We now have a few large rooms with play areas in the consult room itself. The kids can play in the corner and mothers can watch them while talking to us. These triangle kinds of consults where interpreter, doctor and patient form a triangle needs multiple adaptations to suit the clients". Figure 11 further reports three different room layouts where changing the set up made positive changes to the consult.

\section{DISCUSSION}

\section{Application of Theoretical Framework to Study Findings}

Application of CAT contributes to literature by identifying the strategies used by PRS to optimize communication during interpreter mediated SRH consultations with refugee patients. CAT experts propose that accommodation-non-accommodation can be solicited by using five sociolinguistic strategies namely "Approximation", "Interpretability", "Interpersonal control", "Discourse management", and "Emotional expression" (Farzadnia and Giles, 2015). Thematic analysis using CAT framework confirmed that PRS use these strategies frequently to improve communication dynamics and step away from scripted conversations. The first technique known as "Approximation strategy" (Giles et al., 1991) refers to making one's language and communication patterns more similar or dissimilar from another. We will be deliberating on language approximation in a separate paper focusing on "negotiating language and vocabulary" theme and its four sub-themes.

The second technique "Interpretability" (Giles et al., 1991) relate to accommodating our conversation to the other persons level and ability to understand what is going on in the conversation. Studies reveal that both PRS and patients attempt to consider the other's knowledge and disposition (Baker et al., 2011; Scholl et al., 2011; Hewett et al., 2015). In our analysis, we noted multiple instances when PRS appropriately interpreted the non-verbal cues posited by the patient and accommodated by changing the interpreter to reassure the patients of anonymity to disclose private information (Figures 2,3). In contrast, the GP 3, accommodated to the couples needs and worked with an interpreter who was a trusted community elder to create rapport with them (Figure 5).

Third strategy "Interpersonal control" (Giles et al., 1991) refers to how individuals adapt communication based on role relations, relative power, and status. Put another way, an interlocutor deploying this sociolinguistic strategy would opt or not opt to exert power, control the discretion of the other, and direct the communication (Gallois et al., 1988). Our findings in relation to using diverse room set-ups to advance communication, demonstrate the use of interpersonal strategies to accommodate for patient needs. For instance, in Figure 5, the interpreter was handed over greater control of communication, and she decided that it would be better for the couple to sit facing each other and discuss their sexual problems. In another example, in Figure 11, the GP 1 requested the interpreter to sit behind the patient and minimize the sensitivities of having an outsider listening to the couple's private discussion. Clearly, negotiating interpersonal control using flexible room setups helped in breaking communication barriers and obtain successful clinical outcomes.

The fourth technique known as "Discourse management" (Coupland et al., 1988; Giles et al., 1991) relates to the adjustment of communication based on the perceived or stated conversational needs of the other interlocutor (Farzadnia and Giles, 2015). To cite an example, in Figure 6, the Nurse 3 first decides to proceed with the appointment in the presence of the on-site male interpreter to avoid cancellation. Then, she identified the awkwardness and long silences between the interpreter and the patient and terminated the conversation. Subsequently, the nurse booked a new female interpreter on the phone to complete the appointment. Thus, she clearly accommodated for the cultural needs of the patient. Similarly, in Figure 10, the interpreter sensed that the patient was extremely 
upset and responded to her distress by stepping out of the designated interpreter role and asking the patient if she was alright. The patient felt safe by this accommodative behaviour of the interpreter and divulged information about her traumatic rape experience to the phone interpreter.

Finally, "Emotional expression" (Williams et al., 1990), the fifth strategy is to do with responding to the other's emotional and relational needs (Watson and Gallois, 2007). The PRS narrated anecdotes emphasizing the providers' attempts at reassuring patients, reducing their tension, anxiety, and despair, and expressing liking, warmth, and care for them. The incident narrated by Nurse 3 where she sensed the patient's extreme discomfort with the cervical smear test procedure highlights her warmth and caring for the patient. The nurse's decision of abandoning the test and accommodating for the patient's need generated trust between them. Consequently, the patient opened up and revealed the traumatic experiences of the refugee camp where she was raped, and her husband was murdered by the Military Junta.

Ellingson captures seven categories of backstage communication practices (informal impression and information sharing, checking clinic progress, relationship building, space management, training students, handling interruptions, and formal reporting) which can be readily applied to interpreter mediated cross cultural SRH interactions (Ellingson, 2004). To illustrate we will apply this to the vignette in Figure 2 where the $\mathrm{PhD}$ researcher (AT) reports an excerpt from the field notes. In this incident the nurse who managed the distressed patient acted on her "informal impressions" of patient's agitation on hearing the word "interpreter". Then, the nurse did not hurry the patient and provided her with a safe space to narrate her full story in her "broken" English. This "relationship building" alleviated patient's distress and the patient permitted the engagement of a professional interpreter on the phone. Moreover, the use of a phone interpreter is a perfect example of "space management" where the nurse appropriately utilized the existing clinic resources for improving communication. Next, the patient herself offered the nurse a strategy to "handle interruptions" by providing safe words which would signal a suitable time for continuing the sensitive conversation. Finally, the "formal reporting" was done exclusively at the tertiary hospital and the general practice records were left blank to avoid risking breach of patient confidentiality. Clearly, hidden contextual factors were revealed when we applied these seven principles of "backstage communication".

We do not aim to enlist every socio-linguistic or backstage communication strategy that will apply to the anecdotes narrated by the study participants. What is important to note is that if PRS were to engage in "scripted communication" (Gao et al., 2009, page 11) they would reduce their potential to accommodate for cultural sensitivities or individual needs of the patient. Based on our application of CAT strategies to our study findings, we propose that PRS could shift away from scripted consultations and accommodate their communication to the characteristics of the target audience. Scripted communication is not conducive to revelation of behaviour which is different from the cultural norms or relates to any information considered sensitive by the patient. Further, combining CAT with Ellingson's seven categories of backstage communication will provide PRS a realistic framework for adapting the SRH conversations to patient needs.

\section{Comments on Methods and Data Analysis}

Exploring the perspectives of the PRS, this paper presents the challenges of working with interpreters when providing SRH services to Burma born refugees. Using qualitative methods has enabled the researchers to highlight the needs of a minority group that is often excluded from research and service improvement evaluations.

In the results section, we quoted two excerpts (Figures 2, 10) from the field note diaries where we specifically highlight the subthemes of "privacy" and "telephone vs. face-to-face interpreting". Field notes and verbatim interview transcriptions are well recognized techniques of recording social discourses (Tessier, 2012). However, it is noteworthy that what is recorded on tape depends on how those who are recorded react to its presence (Hayes and Mattimoe, 2004). The participants, to the $\mathrm{PhD}$ researchers surprise requested the audio recorder to be turned off while they narrated the two incidents (Figures 2, 10).

In clinical practice, any adverse events or risks identified are documented in the "critical incident reporting systems -communication related section". This is a well-recognized part of adverse event prevention strategies (Ahluwalia and Marriott, 2005; Mahajan, 2010). Although the incidents documented in the research field notes (Figures 2, 10), at the request of participants, have clear clinical implications, both the interviewees felt that there were no secure reporting channels available to them. The study participants gave permission for these stories to be used in any publication.

For a long time, the research team deliberated on whether and how should this information be used. The spectral presence of the "off record" information, shaped the research in multiple ways. Firstly, it clarified our understanding of the nuances of communication in sensitive SRH matters and actively explore the complexities of working with interpreters in depth. Secondly, on a practical level this off record information provided more context to the research and guided us in selecting subsequent people for interviewing which we may have otherwise missed. Thirdly, it created a vocabulary for framing questions and directed probing of the identified problematic areas.

The utility of "off record" information has been documented by other qualitative researchers working on a diverse range of sensitive subjects such as refugee heath (Temple and Moran, 2006), controversial laws (Brooks, 2014; Skinner, 2014), governmental policies (Belcher and Martin, 2019), illegal migrants (Pallister-Wilkins et al., 2020) etc. Interviewers have acknowledged that moment of self-doubt and sense of failure that accompanies the request to switch off the recorder in the middle of the interview (Dundon and Ryan, 2010; Nakane, 2011; Jacobsson and Akerström, 2013). We believe that future researchers working in SRH with refugee 
populations will benefit from this discussion on the place of "off the record" data.

\section{Comments on Sub-themes Privacy and Confidentiality}

Codes of ethics and standards of practice for professional interpreters emphasize the need for confidentiality in all translated conversations (National Council on Interpreting in Health Care (U.S.A). 2005; Healthcare Interpretation Network (Canada), 2007; Australian Institute of Interpreters and Translators Inc., 2012; New Zealand Society of Translators and Interpreters, 2013; National Register of Public Service Interpreters, 2016). Despite, these professional expectations all study participants voiced concerns about maintaining privacy in interpreted SRH consults. Studies conducted in the USA (Morris et al., 2009; McGinnis, 2012; Krumtum, 2014), Canada (Newbold and Willinsky, 2009; McKeary and Newbold, 2010), UK (Wilson et al., 2007; Tribe and Tunariu, 2009), Australia (Hach, 2012; Riggs et al., 2017; Mengesha et al., 2018a) and New Zealand (Gray et al., 2017) indicated that both PRS and patients, were equally perturbed about confidentiality issues. Refugees often live in small communities and there was a high likelihood that patients knew the interpreters outside the consult (Leanza et al., 2014).

As a result, health care providers may assume that the patients will prefer family members to professional interpreters but in sensitive SRH consults this cannot be assumed (Robb and Greenhalgh, 2006; Gadon et al., 2007; Ho, 2008; Barron et al., 2010; Gray et al., 2011; Thompson et al., 2013). Contrasting findings from researchers working with other refugee groups reveal that most women felt embarrassed about discussing female personal health issues in front of their family members. The presence of relatives was described as a barrier which prevented ladies from talking openly about their health concerns, and they spoke of inventing sickness and actually getting prescribed medications for a fake ailment than the real one (Barron et al., 2010). This is an alarming fact and raises the possibility of medical errors. In order to provide the middle path, which has the comfort of anonymity and the efficiency of professional interpreters, study participants have suggested the use of telephone interpreters (Huang and Phillips, 2009) in sensitive SRH consults.

\section{Interpreters' Identity}

The interpreter role has been traditionally conceptualized as a conduit transmitting messages between parties reliably and without distortion (Dysart-Gale, 2005; Leanza, 2005). This is a neutral role where the interpreter strives to be invisible from the consult (Bancroft, 2005; Hsieh, 2006). Our study reports findings that contradict this invisible identity and brings forward a notion where diverse aspects of interpreter's identity influence the dialogue. The experienced Karen interpreter (Figure 5) deviated from the conduit model and used her identity as a trusted community elder positively to resolve the sexual discord in between partners. Her insider's knowledge assisted the GP and the sex therapist to plan the session and enabled them to break down the barriers of communication for the couple.

These findings of interpreters acting as a cultural mediator, or physician's aid is also supported by past literature (Hudelson, 2005;
Hsieh, 2007; Fatahi et al., 2008; Rosenberg et al., 2008; Hsieh, 2010; Leanza et al., 2013; Gartley and Due, 2017). In addition, policies and guidelines related to working with interpreters cautions the health care providers regarding the influence of interpreter's identity on SRH consults (Rosenberg et al., 2006; Tribe and Thompson, 2008; Leanza et al., 2014; Federation of Ethnic Communties Council of Australia, 2016; Migrant and Refugee Women's Health Partnership, 2019). Our analysis re-affirms that the background and social status of the interpreter can remarkably alter the course and outcome of consult (Sleptsova, 2007). In the examples (Figures 2, 3), patients were hesitant to discuss termination of pregnancy, and contraception in the presence of interpreters previously known to them. However, in the comfort of anonymity (telephone interpreters), patients made their wishes known immediately.

Our analysis suggests that it will be better to plan all SRH consults, with a pre-consult meet separately with the interpreter. In this meeting, the health care providers can confirm that the interpreter speaks the same dialect, has experience of working in SRH and will be comfortable working within this arena. The mental health clinicians have specifically designed best practice guidelines which offer advice on similar lines (Raval, 2006; Hlavac, 2017; Tribe and Thompson, 2017). Tribe et al. recommend "spending $10 \mathrm{~min}$ before the session to discuss how you are going to work together, to explain the objective of the meeting and to share any relevant cultural and contextual information which are likely to inform the situation" (Tribe and Thompson, 2008). Our research findings suggest that this investment of time would also be of benefit for SRH consultations in refugee settings.

\section{Gender}

Accessing SRH services is not only about finding a health center, but also finding an environment that is comfortable and understanding of their cultural needs (Day, 2001; DixonWoods et al., 2001; Ahmed and Bates, 2017). Our analysis related to the gender matching of interpreters to improve the comfort of Burma born women is consistent with previous studies (Bischoff et al., 2008; Tribe and Tunariu, 2009; Hasnain et al., 2011; Leanza et al., 2014; Sudbury and Robinson, 2016; Mengesha et al., 2018a; Kingsbury and Chatfield, 2019; Migrant and Refugee Women's, Health Partnership, 2019). PRS described gender matching as common sense and strongly believed that gender discordance presented a major barrier to intimate conversations (Degni et al., 2012). Enquiring of the patient at the time of booking if they have a preference for the gender of the interpreter has been recommended (Leanza et al., 2014; Ussher et al., 2017; Migrant and Refugee Women's, Health Partnership, 2019). Psychologists working with victims of violence and sexual assault suggest that female interpreters may be chosen as default as they are more likely to be acceptable to patients of either gender (Leanza et al., 2014; Tribe and Thompson, 2017).

PRS also pointed out that professional training and experience decreased the need of gender matching and many experienced health care providers are absolutely fine with male interpreters (Mengesha et al., 2018a, page 203). This is a consistent theme found in literature where trained interpreters, because of their professionalism, matter of fact attitude and vast experience in the 
field can negotiate the gender barriers in SRH consults with ease (Miletic et al., 2006; Sleptsova, 2007; Barron et al., 2010).

\section{Family Member Versus Professional Interpreters}

PRS demonstrated a clear preference for professional interpreters compared to family members. The best practice advice (Queensland Government: Queensland Health, 2007; MacFarlane et al., 2009; Tribe and Lane, 2009; NSW Health Care Interpreter Service, 2011; Flores et al., 2012; Leanza et al., 2014; Tyrrell et al., 2016; Migrant and Refugee Women's Health Partnership, 2019) echoes this preference. However, there is literature that questions the notion that health care providers should never work with family members as interpreters (Robb and Greenhalgh, 2006; Karliner et al., 2007; Ho, 2008; Rosenberg et al., 2008; MacFarlane et al., 2009; Gray et al., 2011).

Ethnographic studies examining interpreted consultations report that family members are preferred by many refugee communities. The reasons include relationship of trust in between family members (Robb and Greenhalgh, 2006), background knowledge of the patient (Rosenberg et al., 2007) and the ability to keep things within the family (Leanza et al., 2014). On examining the entire interpreted consultations, "family members do add crucial contextual information and have comforting and calming presence in the consults" (Gray et al., 2011, page 241). Our study participants emphasized that family members are still used because of resource limitations. Parallel findings have been reported by other authors which document high use of family members in emergency situations (Cox and Gutiérrez, 2016; Wang, 2016; Abbato et al., 2018), birthing suites (Yelland et al., 2017) and in-patient encounters (Blay et al., 2018).

In Australia, Telephone Interpreting Services (TIS) are available cost free, $24 \mathrm{~h}$ a day across all health settings for all patients (Boyle et al., 2018; Australian Governement: Department of Home Affairs, 2020). Failure to provide these services is considered discriminatory and illegal (Medical Board of Australia, 2014). Despite the provision of free services and round the clock availability, Australian studies evaluating the uptake of professional interpreters reveal low uptake and utilization in health care settings (Phillips and Travaglia, 2011; Blay et al., 2018; White et al., 2018). When questioned regarding the reasons for this low uptake health care providers described "taking the path of least resistance" (Huang and Phillips, 2009) and proceeding with consultations without interpreters. Multiple researchers have interviewed doctors who have reported that they started taking a history and treating acute symptoms without an interpreter or at times, without talking to the patient, especially during busy shifts (Garrett et al., 2008; Huang and Phillips, 2009; Hsieh, 2015; Jaeger et al., 2019). Many current practices regarding telephone interpreter services were also brought to light where reception staff defer the decision of working with an interpreter to doctors, which often can be too late. There are some health care providers who were still unfamiliar with the process of booking an interpreter (Huang and Phillips, 2009). Other health care practitioners have reasoned that organizing an interpreter is prohibitively time consuming. Many believed that interpreters are not available out of business hours, and all interpreters must be prebooked and thus their services cannot be availed in an acute situation (Ryan et al., 2017).
In addition, the PRS discussed the inappropriateness of working with children to communicate SRH matters to parents. Participants were worried that children do not always have the required vocabulary skills or the maturity to deal with health issues of adults (Giordano, 2007; Leanza et al., 2014). Previous research indicates that when refugee women's opinion about interpreters was solicited, they preferred professional interpreters but were candid in sharing their concerns of confidentiality (Barron et al., 2010; Gray et al., 2017). Ho et al. present a solution that linguistic sensitivity and confidentiality problems do not apply to every case (Ho, 2008). There is a role of trained and family interpreters in health services depending on the availability, patient preference and clinical situation (Rosenberg et al., 2007; Rosenberg et al., 2008; Nápoles et al., 2010). Gray et al. (2011, page 245) conclude that the clinicians need to "understand how to make good judgments on interpreter choice, case by case at that moment in time".

\section{Telephone Versus On-Site Interpreters in SRH}

Participants discussed attributes that they felt were different for onsite interpreting vs. telephone interpreting. As in previous research, on-site interpreting (also referred to as face-to-face interpreting) emerged as a clear preference. PRS felt that the physical presence of an interpreter who is immersed in the dialogue, and able to see the patient's facial expressions and body language will inevitably improve communication efficacy (Locatis et al., 2010; Ozolins, 2012; Riggs et al., 2012).

Unique to our findings, was the unanimous acknowledgement of the role of the telephone interpreter in SRH consults. Telephone interpreting has multiple advantages such as round the clock availability, wider range of languages, professional skill of interpreter is assured and flexibility of working from a remote location for the interpreter (Gracia-García, 2002; Phillips, 2013). Despite having the above benefits, some researchers have described it as "lesser of the two evils" meaning a good interpreter at a distance is better than an untrained family member or none at all (Gracia-García, 2002; Leanza et al., 2010). The findings of our study underscore the significance of "comfort of anonymity" (Miletic et al., 2006) provided by telephone interpreter services in SRH consultations.

Participants offered several examples to explain how telephone interpreters helped in breaking communication barriers. The telephone interpreter was a communication link who is neither an insider who may judge the patients or an outsider who may intrude into their private world. Published research also confirmed that gender of the interpreter mattered much less over the phone (Hadziabdic and Hjelm, 2013). Past studies from court rooms have also noted that in situations which may be embarrassing for the patient, telephone interpreting service was an excellent option for cross-language communication (Mikkelson, 1998; Braun, 2015a).

It is noteworthy that participants brought forward the technical challenges of working with a telephone interpreter in genital examination. Ethnographic studies confirm these findings. Many of the testing situations stem from face-to-face conversations between two primary participants using a speaker phone with interpretation by a remote telephone interpreter. This 
situation can be extremely demanding because of poor sound quality, background noise, problems in hearing or simply being in a room not set up for genital examinations with loudspeaker phones (Lee, 2007; Price et al., 2012; Wang, 2018).

Consult rooms should have the provision of moving the speaker phone to a port behind the curtain to minimize interference. Another option in the current world of cordless or cellular phones, could be re-directing the phone to a cellular phone and to use the speaker phone option on the cellular device. Although redesigning process of service delivery is a challenge, it is not unattainable. Small changes can go a long way. As an example, of service delivery modification, a large public maternity hospital introduced video conferencing for remote interpreting when onsite interpreters were not available and it was well accepted by both patients and doctors (Schulz et al., 2015). We suggest that this is a viable way forward as video-camera function can be switched on (function as on-site interpreters) or off (function as telephone interpreters) depending on the requirements of the patient. In the current situation of a highly contagious COVID 19 pandemic, tele-conferencing and video-interpreting have been adopted as the preferred option to minimize face to face contact between individuals. For future research, we recommend wide-spread evaluation of videoconferencing (Korak, 2012; Braun, 2015b; Havelka, 2020) in SRH consultations in refugee settings.

\section{Setting up the Consultation Room}

Through mindful placing of chairs and desk, our study highlights how PRS accommodated for diverse patient needs. The three scenarios quoted (Figure 11) demonstrated that being conscious of the spatial orientation and arrangement of the consult room will improve communication. The simple act of moving away from the stereotypical consult room organization for triadic consultations, showed deep thinking and flexibility which assisted in creating an environment conducive for sensitive disclosures.

These room orientations have all been documented in ethnographic literature (Miletic et al., 2006; Queensland Government: Queensland Health, 2007; Fatahi et al., 2008; Centre for Culture Ethnicity \& Health (CEH), 2014) but what is important is the creativity of the practitioners to make simple changes that can have positive consequences to improve the trust (Robb and Greenhalgh, 2006) between patient and providers.

\section{Implications for Clinical Practice}

Our findings have strengthened the notion that in cross-cultural SRH settings (Croucher and Kramer, 2017) involving people of refugee backgrounds, a fixed conduit model of interpreting is unrealistic. It is always good practice to design a code of conduct for all professionals including interpreters to benchmark standards. However, it is even more important to acknowledge that each patient brings their own social, cultural conventions, beliefs and prejudices to the clinical encounter (Croucher and Kramer, 2017) and the final interaction will always be fluid and in the moment of time (Dutta, 2016).

We propose that CAT would be a comprehensive approach to understand interpreter medicated cross cultural SRH interactions in refugee settings. First it would act as a dynamic theoretical framework to unpack the interpersonal and intergroup aspects of provider-interpreter-patient interaction. Secondly the mutuality of the interaction flow between providers', interpreters', and patients' contributions-verbal and nonverbal-will be accounted. Thirdly, it will provide room for identifying adaptive socio-linguistic communication strategies in the sensitive SRH consultations of refugee settings. Finally, we would encourage PRS to step beyond apparent conversations and acknowledge background factors for holistic improvement in communication.

Therefore, for a successful triadic SRH interaction, a fluidity of role is expected from health care provider and interpreters. This fluidity is better described as "mundane creativity" (Roberts, 2011) where the health care providers and interpreters adapt to create an environment conducive to SRH consults (Penn and Watermeyer, 2012). We do not mean that the sexual health dialogue should be normalized as "go with the flow" but rather be seen as a highly planned and practiced activity which creates expert providers and interpreters who follow best practice and adapt skillfully (or with mundane creativity) to suit the patients' requirements (Dutta, 2014).

\section{STRENGTHS AND LIMITATIONS}

Although we focus on migrants from Burma, our finding has relevance in primary care, particularly in countries accepting refugee communities for settlement. The reasons for this applicability are manifold. Firstly, this research is as comprehensive as possible in the given scenario encompassing diverse opinions of a myriad of refugee health service providers. In addition, the research team was comprised of experts from diverse backgrounds and experiences in multiple aspects of refugee sexual health issues. Based on the rich data collected and inductive analysis by refugee health practitioners we have not only incorporated contextual information but explored the provider side of this triadic interaction. Secondly, the study acknowledges the cultural, social and language barriers associated with interpretation in refugee settings regarding SRH consults. This was made possible because the PhD student (interviewer) was an ethnically unmatched interviewer (not from Burma) and her identity created a sense of anonymity for all PRS. Consequently, it was easier to be critical of the health system, cultural norms, or any existing practices which the participants wanted to emphasize. Her newness to Australian health system and traditions of Burma also helped, as participants did not presume previous knowledge and shared minute details of their experience. Thirdly, the paper unpacks tensions, uncertainties, ambivalence experienced by health care providers in triadic SRH consults with refugee patients. These incidents also pointed to simple solutions for managing these everyday problems.

A potential limitation of the study is the degree of flexibility allowed in the interview and addition of new group of participants to understand the issue from all sides (decision to 
include interpreters, bilingual support workers and settlement practitioners on the recommendations of GPs and nurses). These strategies are congruent with the nature of iterative interviewing and are in line with the tenets of qualitative research. This inclusion of diverse service providers helped us to understand the overall picture and theme saturation was achieved. Secondly, the number of participating PRS is relatively small, but with the depth of data collected and theme saturation we decided to stop recruitment after 29 interviews. Another limitation is the missing views of refugee families from Burma; however, we plan to interview them in the next phase of this ongoing research. Finally, we acknowledge that our results are based on health care settings of sub-urban Victoria in Australia and may need some adaptation to other settings which have different health systems.

\section{CONCLUSION}

When patients belong to culturally and linguistically diverse groups, a refugee background, and have limited experience of Western health care systems, it is often challenging to provide appropriate, meaningful and responsive SRH services (Dutta, 2010; Ahmed et al., 2016). Interpreters are expected to bridge this gap but there is limited advice on what constitutes best practice when working with them in SRH consults. In essence, this paper presents perspectives of care givers regarding interpretation related issues in providing SRH services to Burma born refugees of diverse ethnicities. PRS highlighted the day-to-day issues related to interpretation such as confidentiality, gender matching, telephone vs. on-site interpreting, family vs. professional interpreters and some of the communication dynamics of delivering SRH care to Burma born refugees settled in Melbourne area. Our findings are in line with other existing literature and when the approach of the PRS is nonaccommodative or culturally insensitive, it can render all SRH issues to become a source of distress to the patient. We hope that PRS who work with different refugee populations across the globe will identify with these everyday challenges and develop strategies tailored to the needs of their local refugee communities.

\section{DATA AVAILABILITY STATEMENT}

The dataset presented in this article are not readily available because it consists of interviews of people working with a small community of refugees settled in the City of Wyndham in Victoria. The study explores a relatively sensitive topic, that is sexual and reproductive health of refugees from Burma settled

\section{REFERENCES}

Abbato, S., Ryan, J., Skelly, C., and Good, P. (2018). The other side of "getting by": a case study of interpreting provision decision-making and consequences for patients. Cogent Med. 5 (1), 1483096. doi:10.1080/2331205X.2018. 1483096 in this area. Due to the small sample size, there is a risk of loss of confidentiality for the study participants themselves. In addition, the incidents narrated may have potential identifiable information about the members of the community. Requests to access datasets should be directed to Dr Amita Tuteja at amita.tuteja@unimelb.edu.au; nidhikrishan2014@gmail.com.

\section{ETHICS STATEMENT}

The studies involving human participants were reviewed and approved by Human Research Ethics Committee, University of Melbourne. The patients/participants provided their written informed consent to participate in this study.

\section{AUTHOR CONTRIBUTIONS}

All authors contributed to conception and design of the study. AT, MTS, LS and LM analyzed and interpreted the data. AT, MTS, LS, ER drafted the article and revised it critically for important intellectual content. All authors contributed to manuscript revision, and final approval of the version to be published.

\section{FUNDING}

The University of Melbourne awarded the PhD student (AT) with the Melbourne International Fee Remission Scholarship and Melbourne International Research Scholarship and is the prime contributor towards the funding of research.

\section{ACKNOWLEDGMENTS}

We are grateful to the practice manager of Utopia Refugee and Asylum Seekers Health, Hoppers Crossing, Lynette $\mathrm{O}^{\prime}$ Dwyer for her invaluable assistance in organizing the interviews with immaculate attention to details. In addition, we are also grateful to Professor Phyllis Lau and Dr. Raj Tuteja for their encouragement and support in AT's PhD journey in the University.

\section{SUPPLEMENTARY MATERIAL}

The Supplementary Material for this article can be found online at: https://www.frontiersin.org/articles/10.3389/fcomm.2021.633855/ full\#supplementary-material.

Ahluwalia, J., and Marriott, L. (2005). Critical incident reporting systems. Semin. Fetal Neonatal Med. 10 (1), 31-37. doi:10.1016/j.siny.2004.09.012

Ahmed, R., and Bates, B. R. (2017). Patients' fear of physicians and perceptions of physicians' cultural competence in healthcare. J. Commun. Healthc. 10 (1), 55-60. doi:10.1080/17538068.2017.1287389

Ahmed, R., Bates, B. R., and Romina, S. M. (2016). Assessing the influence of patients' perceptions of physicians' cultural competence on patient satisfaction 
in an Appalachian Ohio context. Howard J. Commun. 27 (4), 403-421. doi:10. 1080/10646175.2016.1211569

Ahmed, R. (2018). Challenges of migration and culture in a public health communication context. J. Public Health Res. 7 (1508), 92-94. doi:10.4081/ jphr.2018.1508

Asian and Pacific Islander American Scholarship Fund (2014). Invisible newcomers Refugees from Burma/Myanmar and Bhutan in the United States [online]. Association for asian American studies (AAAS). Available at: https://apiascholars. org/wp-content/uploads/2019/04/APIASF_Burma_Bhutan_Report.pdf (Accessed June 27, 2020).

Australian Bureau of Statistics (2019). 2016 census quick stats country of birth: people in Australia who were born in Myanmar [Online]. Available at: https://quickstats.censusdata.abs.gov.au/census_services/getproduct/census/ 2016/quickstat/5101_036 (Accessed March 7, 2020).

Australian Governement Department of Home Affairs (2020). Translating and interpreting service [Online]. Available: https://www.tisnational.gov. au/en/Agencies/Charges-and-free-services/About-the-Free-InterpretingService (Accessed August 11, 2020).

Australian Institute of Interpreters and Translators Inc (2012). AUSIT code of ethics and code of conduct [Online]. Available: https://ausit.org/wpcontent/uploads/2020/02/Code_Of_Ethics_Full.pdf (Accessed August 8, 2020).

Baker, S. C., Gallois, C., Driedger, S. M., and Santesso, N. (2011). Communication accommodation and managing musculoskeletal disorders: doctors' and patients' perspectives. Health Commun. 26 (4), 379-388. doi:10.1080/ 10410236.2010 .551583

Bancroft, M. (2005). The interpreters world tour: an environmental scan of standards of practice for interpreters [online]. Available at: https://www. ncihc.org/assets/documents/publications/NCIHC\%20Environmental\%20Scan. pdf. (Accessed November 20, 2020).

Barron, D. S., Holterman, C., Shipster, P., Batson, S., and Alam, M. (2010). Seen but not heard-ethnic minorities' views of primary health care interpreting provision: a focus group study. Prim. Health Care Res. Dev. 11 (02), 132-141. doi:10.1017/S1463423609990399

Barron, S. (2007). Refugees from Burma: their backgrounds and refugee experiences. Washington DC, USA: Center for Applied Linguistics, Cultural Orientation Resource Center.

Belcher, O., and Martin, L. (2019). "The problem of access: site visits, selective disclosure, and freedom of information in qualitative security research," in Secrecy and methods in security research: a guide to qualitative fieldwork, Editors M. D. Goede, E. Bosma, and P. Pallister-Wilkins (New York, NY: Routledge), 33-47.

Bischoff, A., Hudelson, P., and Bovier, P. A. (2008). Doctor-patient gender concordance and patient satisfaction in interpreter-mediated consultations: an exploratory study. J. Trav. Med. 15 (1), 1-5. doi:10.1111/j.1708-8305.2007.00163.x

Blay, N., Ioannou, S., Seremetkoska, M., Morris, J., Holters, G., Thomas, V., et al. (2018). Healthcare interpreter utilisation: analysis of health administrative data. BMC Health Serv. Res. 18 (1), 348. doi:10.1186/ s12913-018-3135-5

Blount, A. J., and Acquaye, H. E. (2018). Promoting wellness in refugee populations. J. Counsel. Dev. 96 (4), 461-472. doi:10.1002/jcad.12227

Botfield, J. R., Newman, C. E., and Zwi, A. B. (2016). Young people from culturally diverse backgrounds and their use of services for sexual and reproductive health needs: a structured scoping review. Sex. Health 13 (1), 1-9. doi:10.1071/ SH15090

Bouman, W. P., and Arcelus, J. (2001). Are psychiatrists guilty of 'Ageism' when it comes to taking a sexual history? Int. J. Geriatr. Psychiatr. 16(1), 27-31. doi:10. 1002/1099-1166(200101)16:1<27::AID-GPS267>3.0.CO;2-S

Boyle, J., Willey, S. M., and Abbasova, G. (2018). Supporting better outcomes for migrant and refugee women. $O$ \& G Magazine 20 (1), 1.

Braun, S. (2015a). "Remote interpreting," in Routledge handbook of interpreting, Editors H. Mikkelson and R. Jourdenais (London/New York: Routledge), 352-367.

Braun, S. (2015b). "Videoconference interpreting," in Routledge encyclopaedia of interpreting studies, Editor F. Pöchhacker (London/New York: Routledge), 437-438.

Brisset, C., Leanza, Y., and Laforest, K. (2013). Working with interpreters in health care: a systematic review and meta-ethnography of qualitative studies. Patient Educ. Counsel. 91 (2), 131-140. doi:10.1016/j.pec.2012.11.008
Brooks, A. (2014). "Controversial, corrupt and illegal: ethical implications of invetsigating difficult topics-Reflections on fieldwork in southern Africa," in Fieldwork in the global South, Editor J. Lunn (London, UK: Routledge), 34-48. CDC (2016). Burmese refugee health profile [Online]. Atlanta, Georgia: Centers for Disease Control and Prevention. Available: https:/www.cdc.gov/immigrantrefugeehealth/pdf/ burmese-refugee-health-profile.pdf (Accessed June 20, 2020).

Centre for Culture Ethnicity \& Health (CEH) (2014). Interpreter information sheet 1: interpreters: an introduction [Online]. Available: https://www.ceh.org.au/ wp-content/uploads/2015/12/LS1_Interpreters-an-introduction.pdf (Accessed August 11, 2020).

Coupland, N., Coupland, J., Giles, H., and Henwood, K. (1988). Accommodating the elderly: invoking and extending a theory. Lang. Soc. 17 (1), 1-41.

Cox, A., and Gutiérrez, R. L. (2016). "Interpreting in the emergency department: how context matters for practice," in Mediating emergencies and conflicts: frontline translating and interpreting, Editor F. M. Federici (London, UK: Palgrave Macmillan), 33-58.

Croucher, S. M., and Kelly, S. (2019). "Measurement in intercultural and crosscultural communication," in Communication research measures III: a sourcebook, Editors. E. E. Graham and J. P. Mazer (New York, NY: Routledge), 141-159.

Croucher, S. M., and Kramer, E. (2017). Cultural fusion theory: an alternative to acculturation. Journal of International and Intercultural Communication 10 (2), 97-114. doi:10.1080/17513057.2016.1229498

Croucher, S. M. (2020). The importance of culture and communication[Online]. Front. Commun. 5(61). Available: https://www.frontiersin.org/article/10.3389/ fcomm.2020.00061 (Accessed November 20, 2020).

Culturalatlas.sbs.com.au (2020). Cultural Atlas: Myanmar [Burmese] Culture [Online]. Australia. Available: https://culturalatlas.sbs.com.au/burmese-myanmar-culture/ myanmar-burmese-culture-other-considerations (Accessed June 20, 2020).

Day, S. (2001). Choosing and using services for sexual health: women's views. Sex Trans. Infect. (77), 305-308. doi:10.1136/sti.77.5.305

Degni, F., Suominen, S., Essén, B., El Ansari, W., and Vehviläinen-Julkunen, K. (2012). Communication and cultural issues in providing reproductive health care to immigrant women: health care providers' experiences in meeting Somali women living in Finland. J. Immigr. Minority Health 14 (2), 330-343. doi:10. 1007/s10903-011-9465-6

Dehlendorf, C., and Rinehart, W. (2010). Communication in reproductive health: intimate topics and challenging conversations. Patient Educ. Counsel. 81 (3), 321-323. doi:10.1016/j.pec.2010.11.001

Department of Health and Human Services (State Government of Victoria) (2017). Women's sexual and reproductive health key priorities : 2017-2020 [Online]. Australia. Available: https://www2.health.vic.gov.au/about/publications/ policiesandguidelines/womens-sexual-health-key-priorities (Accessed August 6, 2020).

Department of Health (Australian Government) (2018). Fourth national sexually transmissible infections strategy (2018-2022) [Online]. Australia. Available: https://wwwl.health.gov.au/internet/main/publishing.nsf/Content/ohp-bbvs1/\$File/STI-Fourth-Nat-Strategy-2018-22.pdf (Accessed August 6, 2020).

Dixon-Woods, M., Stokes, T., Young, B., Phelps, K., Windridge, K., and Shukla, R. (2001). Choosing and using services for sexual health: a qualitative study of women's views. Sex. Transm. Infect. 77 (5), 335-339. doi:10.1136/sti.77.5.335

Dundon, T., and Ryan, P. (2010). Interviewing reluctant respondents: strikes, henchmen, and Gaelic games. Organ. Res. Methods 13 (3), 562-581. doi:10. 1177/1094428109335571

Dutta, M. J. (2014). A culture-centered approach to listening: voices of social change. Int. J. List. 28 (2), 67-81. doi:10.1080/10904018.2014.876266

Dutta, M. J., Comer, S., Teo, D., Luk, P., Lee, M., Zapata, D., et al. (2018). Health meanings among foreign domestic workers in Singapore: a culture-centered approach. Health Commun. 33 (5), 643-652. doi:10.1080/10410236.2017. 1292576

Dutta, M. J. (2016). Cultural context, structural determinants, and global health inequities: the role of communication [online]. Front. Commun. 1 (5). Available: https://www.frontiersin.org/article/10.3389/fcomm.2016. 00005 (Accessed November 21, 2020).

Dutta, M. J. (2010). The critical cultural turn in health communication: reflexivity, solidarity, and praxis. Health Commun. 25 (6-7), 534-539. doi:10.1080/ 10410236.2010.497995

Dwivedi, R., O’Donnell, M., and Jankowski, K. (2019). "Immigrant and refugee adolescent care: challenges and opportunities," in Promoting health equity 
among racially and ethnically diverse adolescents, Editors L. Barkley, M. V. Svetaz, and V. L. Chulani (Cham, Switzerland: Springer), 189-202.

Dysart-Gale, D. (2005). Communication models, professionalization, and the work of medical interpreters. Health Commun. 17 (1), 91-103. doi:10.1207/ s15327027hc1701_6

Ellingson, L. L. (2004). Communicating in the clinic: negotiating frontstage and backstage teamwork. Cresskill, NJ: Hampton Press.

Ellingson, L. L. (2006). Embodied Knowledge: writing researchers' bodies into qualitative health research. Qual. Health Res. 16 (2), 298-310. doi:10.1177/ 1049732305281944

Farzadnia, S., and Giles, H. (2015). Patient-provider interaction: a communication accommodation theory perspective. Intern. J. Soc. Cul. Lang. 3 (2), 17-34.

Fatahi, N., Hellström, M., Skott, C., and Mattsson, B. (2008). General practitioners' views on consultations with interpreters: a triad situation with complex issues. Scand. J. Prim. Health Care 26 (1), 40-45. doi:10.1080/02813430701877633

Federation of Ethnic Communties Council of Australia (2016). Australia's Growing Lingusitic Diversity: an opportunity for a strategic approach to language services policy and practice (Full Report) [Online]. Australia. Available at: http://fecca.org. au/wp-content/uploads/2016/09/feccalanguagesreport.pdf (Accessed July 11, 2020).

Feinstein, A. R. (1987). The intellectual crisis in clinical science: medaled models and muddled mettle. Perspect. Biol. Med. 30 (2), 215-230. doi:10.1353/pbm. 1987.0047

Fink, C. (2009). Living silence in Burma : surviving under military rule. Chiang Mai/ London: Silkworm Zed.

Fischer, C. T. (2009). Bracketing in qualitative research: conceptual and practical matters. Psychother. Res. 19 (4-5), 583-590. doi:10.1080/10503300902798375

Fletcher, G. (2013). Of baby ducklings and clay pots: method and metaphor in HIV prevention. Qual. Health Res. 23 (11), 1551-1562. doi:10.1177/ 1049732313508012

Flores, G., Abreu, M., Barone, C. P., Bachur, R., and Lin, H. (2012). Errors of medical interpretation and their potential clinical consequences: a comparison of professional versus ad hoc versus no interpreters. Ann. Emerg. Med. 60 (5), 545-553. doi:10.1016/j.annemergmed.2012.01.025

Foundation House (Victorian Foundation for Surviviors of Torture) (2012). Exploring barriers and facilitators to the use of qualified interpreters in health [Online]. Australia. Available: https://refugeehealthnetwork.org.au/wp-content/ uploads/Interpreters+in+health+discussion+paper+FINAL.pdf (Accessed August 12, 2020).

Gadon, M., Balch, G. I., and Jacobs, E. A. (2007). Caring for patients with limited English proficiency: the perspectives of small group practitioners. J. Gen. Intern. Med. 22 (2), 341-346. doi:10.1007/s11606-007-0311-4

Gallois, C., Franklyn-Stokes, A., Giles, H., and Coupland, N. (1988). "Communication accommodation theory and intercultural encounters: intergroup and interpersonal considerations," in Theories in intercultural communication, Editors Y. Y. Kim and W. B. Gudykunst (Newbury Park, CA: Sage Publications), 157-185.

Gao, G., Burke, N., Somkin, C. P., and Pasick, R. (2009). Considering culture in physician-patient communication during colorectal cancer screening. Qual. Health Res. 19 (6), 778-789. doi:10.1177/1049732309335269

Garrett, P., Dickson, H., Young, L., and Whelan, A. K. (2008). "The Happy Migrant Effect": perceptions of negative experiences of healthcare by patients with little or no English: a qualitative study across seven language groups. Quality and Safety in Health Care 17 (2), 101-103. doi:10.1136/qshc.2007. 022426

Gartley, T., and Due, C. (2017). The interpreter is not an invisible being: a thematic analysis of the impact of interpreters in mental health service provision with refugee clients. Aust. Psychol. 52 (1), 31-40. doi:10.1111/ap.12181

Giles, H., Coupland, N., and Coupland, J. (1991). "Accommodation theory: Communication, context, and consequence," in Contexts of accommodation: developments in applied sociolinguistics, Editors H. Giles, N. Coupland, and J. Coupland (New York, NY: Cambridge University Press), 1-68.

Giordano, S. (2007). Overview of the advantages and disadvantages of professional and child interpreters for limited english proficiency patients in general health care situations. J. Radiol. Nurs. 26 (4), 126-131. doi:10.1016/j.jradnu.2007. 09.002

Gracia-García, R. A. (2002). Telephone interpreting: a review of pros and cons [Online]. Citeseer. Available: http://citeseerx.ist.psu.edu/viewdoc/download;
jsessionid=B6F49FAA529ECA4ED4C0C1B4AED0AA38? doi=10.1.1.570. $5429 \&$ rep $=$ rep $1 \&$ type $=$ pdf $($ Accessed November 21, 2020).

Graneheim, U. H., and Lundman, B. (2004). Qualitative content analysis in nursing research: concepts, procedures and measures to achieve trustworthiness. Nurse Educ. Today 24 (2), 105-112. doi:10.1016/j.nedt.2003.10.001

Gray, B., Hilder, J., and Donaldson, H. (2011). Why do we not use trained interpreters for all patients with limited English proficiency? Is there a place for using family members? Aust. J. Prim. Health 17 (3), 240-249. doi:10.1071/ PY10075

Gray, B., Hilder, J., and Stubbe, M. (2012). How to use interpreters in general practice: the development of a New Zealand toolkit. Journal of Primary Health Care 4 (1), 52-61. doi:10.1071/HC12052

Gray, B., Stubbe, M., and Hilder, J. (2017). Integrating health Navigation and interpreting Services for patients with limited English proficiency [online]. Wellington: Department of Primary Health Care \& General Practice, University of Otago, Wellington (ARCH Group). Available: https://www. otago.ac.nz/wellington/otago657055.pdf (Accessed November 20, 2020).

Hach, M. (2012). Common threads: the sexual and reproductive health experiences of immigrant and refugee women in Australia [Online]. Melbourne: Multicultrual Centre for Women's Health. Available: https://www.mcwh.com.au/downloads/ publications/MCWH_CommonThreads_Report_WEB.pdf (Accessed March 23, 2020).

Hadziabdic, E., and Hjelm, K. (2013). Working with interpreters: practical advice for use of an interpreter in healthcare. Int. J. Evid. Base. Healthc. 11 (1), 69-76. doi:10.1111/1744-1609.12005

Hasnain, M., Connell, K. J., Menon, U., and Tranmer, P. A. (2011). Patientcentered care for muslim women: provider and patient perspectives. J. Wom. Health 20 (1), 73-83. doi:10.1089/jwh.2010.2197

Havelka, I. (2020). Video-mediated remote interpreting in healthcare: analysis of an Austrian pilot project. Babel 66 (2), 326-345. doi:10.1075/babel.00156.hav

Hayes, T., and Mattimoe, R. (2004). "To tape or not to tape: Reflections on methods of data collection," in The real life guide to accounting research, Editors C. Humphrey and B. Lee (London, UK: Elsevier), 359-372.

Healthcare Interpretation Network (Canada) (2007). "National Standard Guide for Community Interpreting Services [Online]." Toronto, Canada. Available at: https://secureservercdn.net/45.40.155.145/13r.c38.myftpupload.com/ wp-content/uploads/2018/06/National-Standard-Guide-for-CommunityInterpreting-Services.v2.pdf (Accessed August 8, 2020).

Hewett, D. G., Watson, B. M., and Gallois, C. (2015). Communication between hospital doctors: underaccommodation and interpretability. Lang. Commun. 41, 71-83. doi:10.1016/j.langcom.2014.10.007

Hinchliff, S., Gott, M., and Galena, E. (2004). GPs' perceptions of the genderrelated barriers to discussing sexual health in consultations: a qualitative study. Eur. J. Gen. Pract. 10 (2), 56-60. doi:10.3109/13814780409094233

Hlavac, J. (2017). Mental health interpreting Guidelines for interpreters [online]. Melbourne, Victoria, Australia: Monash University. Available at: https://aslia. com.au/wp-content/uploads/Monash-Mental-Health-Interpreting-Guidelinesfor-Interpreters-29.XI_.2017.pdf (Accessed August 9, 2020).

Ho, A. (2008). Using family members as interpreters in the clinical setting. J. Clin. Ethics 19 (3), 223-233.

Hsieh, E. (2006). Conflicts in how interpreters manage their roles in provider-patient interactions. Soc. Sci. Med. 62 (3), 721-730. doi:10.1016/j. socscimed.2005.06.029

Hsieh, E. (2007). Interpreters as co-diagnosticians: overlapping roles and services between providers and interpreters. Soc. Sci. Med. 64 (4), 924-937. doi:10.1016/ j.socscimed.2006.10.015

Hsieh, E. (2015). Not just "getting by": factors influencing providers' choice of interpreters. J. Gen. Intern. Med. 30 (1), 75-82. doi:10.1007/s11606-014-3066-8

Hsieh, E. (2010). Provider-interpreter collaboration in bilingual health care: competitions of control over interpreter-mediated interactions. Patient Educ. Counsel. 78 (2), 154-159. doi:10.1016/j.pec.2009.02.017

Huang, Y., and Phillips, C. (2009). Telephone interpreters in general practice bridging the barriers to their use. Aust. Fam. Physician 38, 443-446.

Hudelson, P. (2005). Improving patient-provider communication: insights from interpreters. Fam. Pract. 22 (3), 311-316. doi:10.1093/fampra/cmi015

Humanitarian Crisis Team Myanmar (2019). Myanmar humanitarian needs overview 2020 (December 2019) [Online]. New York, NY: United Nations Office for the Coordination of Humanitarian Affairs (OCHA). Available at: 
https://reliefweb.int/report/myanmar/myanmar-humanitarian-needs-overview2020-december-2019 (Accessed August 5, 2020).

Jacobsson, K., and Åkerström, M. (2013). Interviewees with an agenda: learning from a 'failed' interview. Qual. Res. 13 (6), 717-734. doi:10.1177/1468794112465631

Jaeger, F. N., Pellaud, N., Laville, B., and Klauser, P. (2019). Barriers to and solutions for addressing insufficient professional interpreter use in primary healthcare. BMC Health Serv. Res. 19 (1), 753. doi:10.1186/s12913-019-4628-6

Jain, P., and Krieger, J. L. (2011). Moving beyond the language barrier: the communication strategies used by international medical graduates in intercultural medical encounters. Patient Educ. Counsel. 84 (1), 98-104. doi:10.1016/j.pec.2010.06.022

Karliner, L. S., Jacobs, E. A., Chen, A. H., and Mutha, S. (2007). Do professional interpreters improve clinical care for patients with limited English proficiency? A systematic review of the literature. Health Serv. Res. 42 (2), 727-754. doi:10. $1111 / j .1475-6773.2006 .00629 . x$

Kercood, S., and Morita-Mullaney, T. (2015). Health perceptions and practices of Burmese refugee families: a participatory mixed method study. J. Southeast Asian Amer. Edu. Advan. 10 (1), 8. doi:10.7771/2153-8999.1124

Keygnaert, I. (2014). Sexual violence and sexual health in refugees, asylum seekers and undocumented migrants in Europe and the European neighbourhood: determinants and desirable prevention. [dissertation/ $\mathrm{PhD}$ thesis], Ghent, Belgium, Ghent University.

Kingsbury, D. M., and Chatfield, S. L. (2019). A qualitative metasynthesis of published research exploring the pregnancy and resettlement experience among refugee women. Qual. Rep. 24 (2), 242-257. Available at: https://nsuworks. nova.edu/tqr/vol24/iss $2 / 3$.

Korak, C. A. (2012). Remote interpreting via Skype-a viable alternative to in situ interpreting? The Interpreters' Newsletter 17, 83-102. Available at: http://hdl. handle.net/10077/8614

Krumtum, A. J. (2014). Understanding reproductive health among Burmese refugees in Greeley, Colorado: an ethnographic account. Ursidae: The Undergraduate Research Journal at the University of Northern Colorado 3 (3), 7.

LaMancuso, K., Goldman, R. E., and Nothnagle, M. (2016). "Can i ask that?": perspectives on perinatal care after resettlement among karen refugee women, medical providers, and community-based doulas. J. Immigr. Minority Health 18 (2), 428-435. doi:10.1007/s10903-015-0172-6

Leanza, Y., Boivin, I., and Rosenberg, E. (2010). Interruptions and resistance: a comparison of medical consultations with family and trained interpreters. Soc. Sci. Med. 70 (12), 1888-1895. doi:10.1016/j.socscimed.2010.02.036

Leanza, Y., Boivin, I., and Rosenberg, E. (2013). The patient's Lifeworld: Building meaningful clinical encounters between patients, physicians and interpreters. Commun. Med. 10 (1), 13. doi:10.1558/cam.v10i1.13

Leanza, Y., Miklavcic, A., Boivin, I., and Rosenberg, E. (2014). "Working with interpreters," in Cultural consultation: encountering the other in mental health care, Editors. C. Rousseau, J. Guzder, and L. J. Kirmayer (New York: Springer), $89-114$.

Leanza, Y. (2005). Roles of community interpreters in pediatrics as seen by interpreters, physicians and researchers. Interpreting 7 (2), 167-192. doi:10. 1075/intp.7.2.03lea

Lee, J. (2007). Telephone interpreting-seen from the interpreters' perspective. Interpreting 9 (2), 231-252. doi:10.1075/intp.9.2.05lee

Levinson, W., Lesser, C. S., and Epstein, R. M. (2010). Developing physician communication skills for patient-centered care. Health Aff. 29 (7), 1310-1318. doi:10.1377/hlthaff.2009.0450

Locatis, C., Williamson, D., Gould-Kabler, C., Zone-Smith, L., Detzler, I., Roberson, J., et al. (2010). Comparing in-person, video, and telephonic medical interpretation. J. Gen. Intern. Med. 25 (4), 345-350. doi:10.1093/jrs/ fet005

MacFarlane, A., Dzebisova, Z., Karapish, D., Kovacevic, B., Ogbebor, F., and Okonkwo, E. (2009). Arranging and negotiating the use of informal interpreters in general practice consultations: experiences of refugees and asylum seekers in the west of Ireland. Soc. Sci. Med. 69 (2), 210-214. doi:10.1016/j.socscimed. 2009.04.022

Mahajan, R. (2010). Critical incident reporting and learning. Br. J. Anaesth. 105 (1), 69-75. doi:10.1093/bja/aeq133

Maharaj, N. (2016). Using field notes to facilitate critical reflection. Reflective Pract. 17 (2), 114-124. doi:10.1080/14623943.2015.1134472
McGinnis, K. E. (2012). "You have to have children to be happy:" Exploring Beliefs about Reproduction with Burmese Refugee Women in the United States. [dissertation/graduate thesis]. Tampa, FL: University of South Florida.

McKeary, M., and Newbold, B. (2010). Barriers to care: the challenges for Canadian refugees and their health care providers. J. Refug. Stud. 23 (4), 523-545. doi:10. 1093/jrs/feq038

McMichael, C., and Gifford, S. (2010). Narratives of sexual health risk and protection amongst young people from refugee backgrounds in Melbourne, Australia. Cult. Health Sex. 12 (3), 263-277. doi:10.1080/13691050903359265

Medical Board of Australia (2014). Good medical practice: a code of conduct for doctors in Australia [Online]. Australia: Medical Board of Australia. Available at: https://www.medicalboard.gov.au/Codes-Guidelines-Policies/Code-ofconduct.aspx (Accessed August 11, 2020).

Mengesha, Z. B., Perz, J., Dune, T., and Ussher, J. (2018b). Preparedness of health care professionals for delivering sexual and reproductive health care to refugee and migrant women: a mixed methods study. Int. J. Environ. Res. Public Health 15 (1), 174. doi:10.3390/ijerph15010174

Mengesha, Z. B., Perz, J., Dune, T., and Ussher, J. (2017). Refugee and migrant women's engagement with sexual and reproductive health care in Australia: a socio-ecological analysis of health care professional perspectives. PloS One 12 (7), e0181421. doi:10.1371/journal.pone.0181421

Mengesha, Z. B., Perz, J., Dune, T., and Ussher, J. (2018a). Talking about sexual and reproductive health through interpreters: the experiences of health care professionals consulting refugee and migrant women. Sexual \& Reproductive Healthcare 16, 199-205. doi:10.1016/j.srhc.2018.03.007

Migrant and Refugee Women's Health Partnership (2019). "Guide for clinicians working with interpreters in healthcare settings [Online]." Available at: https:// www.midwives.org.au/sites/default/files/uploaded-content/website-content/ guide_for_clinicians_working_with_interpreters_in_healthcare_settings_ jan2019.pdf (Accessed April 10, 2020).

Mikkelson, H. (1998). Towards a redefinition of the role of the court interpreter. Interpreting 3 (1), 21-45. doi:10.1075/intp.3.1.02mik

Miletic, T., Piu, M., Minas, H., Stankovska, M., Stolk, Y., and Klimidis, S. (2006). Guidelines for working effectively with interpreters in mental health settings [Online]. Melbourne, Australia: Victorian Transcultural Psychiatry Unit. Available at: https://www.researchgate.net/publication/255650088_Guidelines_for_Working Effectively_with_Interpreters_in_Mental_Health_Settings (Accessed November 20, 2020).

Mishler, E. G. (1984). The discourse of medicine: dialectics of medical interviews. Norwood, New Jersey: Ablex Publishing Corporation.

Morris, M. D., Popper, S. T., Rodwell, T. C., Brodine, S. K., and Brouwer, K. C. (2009). Healthcare barriers of refugees post-resettlement. J. Community Health 34 (6), 529-538. doi:10.1007/s10900-009-9175-3

Morris, M. W., Leung, K., Ames, D., and Lickel, B. (1999). Views from inside and outside: integrating emic and etic insights about culture and justice judgment. Acad. Manag. Rev. 24 (4), 781-796. doi:10.2307/259354

Mulhall, A. (2003). In the field: notes on observation in qualitative research. J. Adv. Nurs. 41 (3), 306-313. doi:10.1046/j.1365-2648.2003.02514.x

Muswazi, M., and Nhamo, E. (2013). Note taking: a lesson for novice qualitative researchers. J. Res. Method Edu. 2 (3), 13-17.

Nápoles, A. M., Santoyo-Olsson, J., Karliner, L. S., O’Brien, H., Gregorich, S. E., and Pérez-Stable, E. J. (2010). Clinician ratings of interpreter mediated visits in underserved primary care settings with ad hoc, in-person professional, and video conferencing modes. J. Health Care Poor Underserved 21 (1), 301. doi:10. 1353/hpu.0.0269

Nakane, I. (2011). The role of silence in interpreted police interviews. J. Pragmat. 43 (9), 2317-2330. doi:10.1016/j.pragma.2010.11.013

National Council on Interpreting in Health Care USA. (2005). "National standards of practice for interpreters in health care [Online]." Available at: https://www. ncihc.org/assets/documents/publications/NCIHC\%20National\%20Standards\% 20of\%20Practice.pdf (Accessed August 8, 2020).

National Register of Public Service Interpreters (2016). Code of professional conduct: [Online]. National Register of Public Service Interpreters: UK. Available at: https://www.nrpsi.org.uk/for-clients-of-interpreters/code-ofprofessional-conduct.html (Accessed August 8, 2020).

New Zealand Society of Translators and Interpreters (2013). NZSTI code of ethics and code of conduct [Online]: New Zealand. Available at: https://nzsti.org/ 
Pages/SYSTEM/Utility/Download.aspx?id=976832ed-a16a-46f7-b22fc7050 caae1a8\&newtab=1 (Accessed August 8, 2020).

Newbold, K. B., and Willinsky, J. (2009). Providing family planning and reproductive healthcare to Canadian immigrants: perceptions of healthcare providers. Cult. Health Sex. 11 (4), 369-382. doi:10.1080/ 13691050802710642

Noyori-Corbett, C., and Moxley, D. P. (2017). Resettlement issues among Myanmar refugee women in the early stage of a community-based developmental research project. J. Community Pract. 25 (3/4), 464-487. doi:10.1080/10705422.2017.1354240

NSW Health Care Interpreter Service (2011). Guidelines for working with interpreters: for counselling \& health care staff working with refugees [Online]. NSW, Australia: NSW Health. Available: https://www.swslhd.health.nsw.gov.au/refugee/pdf/ Interpreter_Guidelines.pdf (Accessed August 9, 2020).

Ozolins, U. (2012). Telephone interpreting: understanding practice and identifying research needs. Translation \& Interpreting 3 (2), 33-47. Available at: http:// www.trans-int.org/index.php/transint/article/view/136/93.

Pallister-Wilkins, P., Goede, M. d., and Bosma, E. (2020). Secrecy and methods in security research : a guide to qualitative fieldwork. London/New York: Routledge.

Penn, C., and Watermeyer, J. (2012). When asides become central: small talk and big talk in interpreted health interactions. Patient Educ. Counsel. 88 (3), 391-398. doi:10.1016/j.pec.2012.06.016

Phillips, C. B., and Travaglia, J. (2011). Low levels of uptake of free interpreters by Australian doctors in private practice: secondary analysis of national data. Aust. Health Rev. 35 (4), 475-479. doi:10.1071/AH10900

Phillips, C. (2013). Remote telephone interpretation in medical consultations with refugees: meta-communications about care, survival and selfhood. J. Refug. Stud. 26 (4), 505-523. doi:10.1093/jrs/fet005

Phillips, C. (2010). Using interpreters: a guide for GPs. Aust. Fam. Physician 39 (4), 188.

Price, E. L., Pérez-Stable, E. J., Nickleach, D., López, M., and Karliner, L. S. (2012). Interpreter perspectives of in-person, telephonic, and videoconferencing medical interpretation in clinical encounters. Patient Educ. Counsel. 87 (2), 226-232. doi:10.1016/j.pec.2011.08.006

Queensland Government: Queensland Health (2007). Working with interpreters: guidelines [Online]. Available at: https://www.health.qld.gov.au/_data/assets/ pdf_file/0033/155994/guidelines_int.pdf (Accessed April 21, 2020).

Raval, H. (2006). Mental health training for bilingual co-workers in the context of working with people seeking asylum and refuge. Primary Care Mental Health 4 (1), 37-44.

Refugee Services for National Partnership for Community Training (2017). Refugee wellness community guide: Burma (Myanmar)-Rohingyas [online]. Largo, Florida: Gulf Coast Jewish Family and Community Services. Available: https://gulfcoastjewishfamilyandcommunityservices.org/wp-content/uploads/ 2018/04/NPCT-Burma-Myanamar-Rohingya-Country-Guide.pdf (Accessed June 20, 2020).

Riggs, E., Davis, E., Gibbs, L., Block, K., Szwarc, J., Casey, S., et al. (2012). Accessing maternal and child health services in Melbourne, Australia: reflections from refugee families and service providers. BMC Health Serv. Res. 12 (1), 117. doi:10. 1186/1472-6963-12-117

Riggs, E., Muyeen, S., Brown, S., Dawson, W., Petschel, P., Tardiff, W., et al. (2017). Cultural safety and belonging for refugee background women attending group pregnancy care: an Australian qualitative study. Birth 44 (2), 145-152. doi:10. 1111/birt.12272

Robb, N., and Greenhalgh, T. (2006). "You have to cover up the words of the doctor": the mediation of trust in interpreted consultations in primary care. $J$ Health Organ Manag 20 (5), 434-455. doi:10.1108/14777260610701803

Roberts, C. (2011). "The gatekeeping of health care professionals in superdiverse societies: a case study of general practice", in Comet: communication, medicine and ethics conference, Nottingham, UK, June 30-July 2, 2011.

Rosenberg, E., Leanza, Y., and Seller, R. (2007). Doctor-patient communication in primary care with an interpreter: physician perceptions of professional and family interpreters. Patient Educ. Counsel. 67 (3), 286-292. doi:10.1016/j.pec. 2007.03.011

Rosenberg, E., Richard, C., Lussier, M.-T., and Abdool, S. N. (2006). Intercultural communication competence in family medicine: lessons from the field. Patient Educ. Counsel. 61 (2), 236-245. doi:10.1016/j.pec.2005.04.002
Rosenberg, E., Seller, R., and Leanza, Y. (2008). Through interpreters' eyes: comparing roles of professional and family interpreters. Patient Educ. Counsel. 70 (1), 87-93. doi:10.1016/j.pec.2007.09.015

Ryan, J., Abbato, S., Greer, R., Vayne-Bossert, P., and Good, P. (2017). Rates and predictors of professional interpreting provision for patients with limited English proficiency in the emergency department and inpatient ward. Inquiry 54, 1-6. doi:10.1177/0046958017739981

Sandelowski, M. (2000). Focus on research methods: whatever happened to qualitative description? . Res. Nurs. Health 23 (4), 334-340. doi:10.1002/ 1098-240x(200008)23:4<334::aid-nur9>3.0.co;2-g

Sandelowski, M. (2010). What's in a name? Qualitative description revisited. Res. Nurs. Health 33 (1), 77-84. doi:10.1002/nur.20362

Scholl, J. C., Wilson, J. B., and Hughes, P. C. (2011). Expression of patients' and providers' identities during the medical interview. Qual. Health Res. 21 (8), 1022-1032. doi:10.1177/1049732310393748

Schulz, T., Leder, K., Akinci, I., and Biggs, B.-A. (2015). Improvements in patient care: videoconferencing to improve access to interpreters during clinical consultations for refugee and immigrant patients. Aust. Health Rev. 39 (4), 395-399. doi:10.1071/AH14124

Sharron, H., Merryn, G., and Elisabeth, G. (2005). 'I daresay I might find it embarrassing': general practitioners' perspectives on discussing sexual health issues with lesbian and gay patients. Health Soc. Care Community 13 (4), 345-353. doi:10.1111/j.1365-2524.2005.00566.x

Singh, R. (2018). The art of sexual history taking and barriers faced by residents. Annals of Indian Psychiatry 2 (2), 160-162. doi:10.4103/aip.aip_42_18

Skinner, C. (2014). "You can be jailed here by even me talking to you': dilemmas and difficulties relating to informed consent, confidentiality and anonymity," in Fieldwork in the global South, Editor J. Lunn (London/New York: Routledge), 205-213.

Sleptsova, M. (2007). If the provision of information runs into the language barrier--about the cooperation with interpreters. Therapeutische Umschau. Revue Therapeutique 64 (10), 575-579. doi:10.1024/0040-5930.64.10.575

Smith, R. C. (2002). Patient-centered interviewing: an evidence-based method. Philadelphia, PA: Lippincott Williams \& Wilkins.

Squires, A., and Jacobs, E. A. (2016). Language and communication issues impact healthcare providers around the world. Int. J. Nurs. Stud. 54, 5-6. doi:10.1016/j. ijnurstu.2015.12.002

Street, R. L. (1991). "Accommodation in Medical Consultations," in Contexts of accommodation: developments in applied sociolinguistics, Editors. H. Giles, N. Coupland, and J. Coupland (New York, NY: Cambridge University Press), 131-156.

Sudbury, H., and Robinson, A. (2016). Barriers to sexual and reproductive health care for refugee and asylum-seeking women. Br. J. Midwifery 24 (4), 275-281. doi:10.12968/bjom.2016.24.4.275

Swe, H., and Ross, M. (2010). Refugees from Myanmar and their Health Care Needs in the US: a qualitative study at a refugee resettlement Agency. Int. J. Migrat. Health Soc. Care 6 (1), 15-25. doi:10.5042/ijmhsc.2010.0446

Tao, G., Irwin, K. L., and Kassler, W. J. (2000). Missed opportunities to assess sexually transmitted diseases in U.S. adults during routine medical checkups. Am. J. Prev. Med. 18 (2), 109-114. doi:10.1016/s0749-3797(99)00139-7

Temple, B., and Moran, R. (2006). Doing research with refugees : issues and guidelines. Bristol, UK: Policy Press.

Temple-Smith, M. J., Mulvey, G., and Keogh, L. (1999). Attitudes to taking a sexual history in general practice in Victoria, Australia. Sex. Transm. Infect. 75 (1), 41-44. doi:10.1136/sti.75.1.41

Tessier, S. (2012). From field notes, to transcripts, to tape recordings: evolution or combination? Int. J. Qual. Methods 11 (4), 446-460. doi:10.1177/ 160940691201100410

Thompson, D. A., Hernandez, R. G., Cowden, J. D., Sisson, S. D., and Moon, M. (2013). Caring for patients with limited English proficiency: are residents prepared to use medical interpreters? Academic Medicine: Journal of the Association of American Medical Colleges 88 (10), 1485-1492. doi:10.1097/ ACM.0b013e3182a3479d

Tomlinson, J. (1998). ABC of sexual health: taking a sexual history. BMJ 317 (7172), 1573-1576. doi:10.1136/bmj.317.7172.1573

Tribe, R., and Lane, P. (2009). Working with interpreters across language and culture in mental health. J. Ment. Health 18 (3), 233-241. doi:10.1080/ 09638230701879102 
Tribe, R., and Thompson, K. (2017). Working with interpreters: guidelines for psychologists [Online]. Leicester, UK: The British Psychological Society. Available: https://www.bps.org.uk/sites/www.bps.org.uk/files/Policy/Policy\%20\%20Files/Working\%20with\%20interpreters\%20-\%20guidelines\%20for \%20psychologists.pdf (Accessed August 9, 2020).

Tribe, R., and Thompson, K. (2008). Working with interpreters in health settings: guidelines for psychologists [Online]. Leicester, UK: British Psychological Society. Available: https://blogs.mcgill.ca/tcpsych/files/2013/01/British-PsychologicalSociety-guidelines-wking-with-interpreters.pdf (Accessed November 21, 2020).

Tribe, R., and Tunariu, A. (2009). Mind your language: working with interpreters in healthcare settings and therapeutic encounters. Sex. Relatsh. Ther. 24 (1), 74-84. doi:10.1080/14681990802666023

Tyrrell, L., Duell-Piening, P., Morris, M., and Casey, S. (2016). Talking about health and experiences of using health services with people from refugee backgrounds [Online]. Melbourne, Australia: Victorian Refugee Health Network. Available: http://refugeehealthnetwork.org.au/wp-content/uploads/ Report_2016_September_Victorian-Refugee-Health-Network_Talking-AboutHealth_FINAL-WEB.pdf (Accessed March 23, 2020).

Ulin, P. R. (2002). Qualitative methods: a field guide for applied research in sexual and reproductive health. Durham, North Carolina: Family Health International.

United Nations High Commissioner for Refugees (2019). Global trends: forced displacement in 2018 [Online]. Geneva, Switzerland: UNHCR. Available: https://www.unhcr.org/5d08d7ee7.pdf (Accessed August 11, 2020).

Ussher, J. M., Metusela, C., Hawkey, A. J., and Perz, J. M. (2017). Sexual and reproductive health of migrant and refugee women: research report and recommendations for healthcare providers and community workers [Online]. Sydney, Australia: Western Sydney University. Available: https://www.westernsydney.edu.au/_data/assets/pdf_ file/0020/1225334/SRH_CALD_Report.pdf (Accessed August 11, 2020).

Ussher, J. M., Rhyder-Obid, M., Perz, J., Rae, M., Wong, T. W., and Newman, P. (2012). Purity, privacy and procreation: constructions and experiences of sexual and reproductive health in Assyrian and Karen women living in Australia. Sex. Cult. 16 (4), 467-485. doi:10.1007/s12119-012-9133-6

Wakeman, C. (2009). No time for dreams: living in Burma under military rule. Lanham, MD: Rowman \& Littlefield Publishers.

Wallerstein, N., Oetzel, J. G., Duran, B., Magarati, M., Pearson, C., Belone, L., et al. (2019). Culture-centeredness in community-based participatory research: contributions to health education intervention research. Health Educ. Res. 34 (4), 372-388. doi:10.1093/her/cyz021

Wang, J. (2018). 'Telephone interpreting should be used only as a last resort. 'Interpreters' perceptions of the suitability, remuneration and quality of telephone interpreting. Perspectives 26 (1), 100-116. doi:10.1080/0907676X.2017.1321025
Wang, X. (2016). The Impact of using ad hoc interpreters and professional interpreters on hospital costs and patient satisfaction rates of limited-english-proficient patients in the emergency department. Int. J. Econ. Comm. Manag. 245-257.

Watson, B., and Gallois, C. (2007). "Language, discourse, and communication about health and illness: Intergroup relations, role, and emotional support," in Language, discourse and social psychology, Editors A. Weatherall, B. M. Watson, and C. Gallois (Basingstoke, UK: Palgrave Macmillan), 108-130.

White, J., Plompen, T., Osadnik, C., Tao, L., Micallef, E., and Haines, T. (2018). The experience of interpreter access and language discordant clinical encounters in Australian health care: a mixed methods exploration. Int. J. Equity Health 17 (1), 151. doi:10.1186/s12939-018-0865-2

Williams, A., Giles, H., Coupland, N., Dalby, M., and Manasse, H. (1990). The communicative contexts of elderly social support and health: a theoretical model. Health Commun. 2 (3), 123-143. doi:10.1207/ s15327027hc0203_1

Wilson, R., Saunders, M., and Dumper, H. (2007). Sexual health, asylum seekers and refugees: a handbook for people working with refugees and asylum seekers in England. London, UK: Family Planning Association.

World Health Organization (2016). Action plan for sexual and reproductive health towards achieving the 2030 agenda for sustainable development in Europe leaving no one behind [Online]. Copenhagen, Denmark: World Health Organization. Available at: https://www.euro.who.int/_data/assets/pdf_file/ 0003/322275/Action-plan-sexual-reproductive-health.pdf?ua $=1 \quad$ (Accessed August 6, 2020).

Yelland, J., Biro, M. A., Dawson, W., Riggs, E., Vanpraag, D., Wigg, K., et al. (2017). Bridging the language gap: a co-designed quality improvement project to engage professional interpreters for women duing labour. Aust. Health Rev. 41 (5), 499-504. doi:10.1071/AH16066

Conflict of Interest: The authors declare that the research was conducted in the absence of any commercial or financial relationships that could be construed as a potential conflict of interest.

Copyright (c) 2021 Tuteja, Riggs, Sanci, Mascarenhas, VanVliet, Sangster, McGuinness and Temple-Smith. This is an open-access article distributed under the terms of the Creative Commons Attribution License (CC BY). The use, distribution or reproduction in other forums is permitted, provided the original author(s) and the copyright owner(s) are credited and that the original publication in this journal is cited, in accordance with accepted academic practice. No use, distribution or reproduction is permitted which does not comply with these terms. 